\title{
Unknown Unknowns: Uncertainty About Risk and Stock Returns
}

\author{
Guido Baltussen, Sjoerd van Bekkum, and Bart van der Grient*
}

\begin{abstract}
Stocks with high uncertainty about risk, as measured by the volatility of expected volatility (vol-of-vol), robustly underperform stocks with low uncertainty about risk by $8 \%$ per year. This vol-of-vol effect is distinct from (combinations of) at least 20 previously documented return predictors, survives many robustness checks, and holds in the United States and across European stock markets. We empirically explore the pricing mechanism behind the vol-of-vol effect. The evidence points toward preference-based explanations and away from alternative explanations. Collectively, our results show that uncertainty about risk is highly relevant for stock prices.
\end{abstract}

\section{Introduction}

What determines individual stock returns? Although standard finance theory predicts that only the joint distribution of individual stock returns and the market portfolio should determine stock returns, several reasons exist for why not only covariances matter for asset pricing but also the distributional characteristics of individual stock returns. Volatility is the leading example of such a characteristic, as it seems to robustly determine the cross section of stocks (e.g., Ang, Hodrick, Xing, and Zhang (2006), (2009)). Several theories explain these findings, offering different reasons for why volatility matters as a stock characteristic. ${ }^{1}$

\footnotetext{
*Baltussen, baltussen@ese.eur.nl, van Bekkum (corresponding author), vanbekkum@ese.eur.nl, Erasmus University Rotterdam Erasmus School of Economics; and van der Grient, b.van.der.grient@robeco.com, Robeco Asset Management. This paper has benefited greatly from extensive discussions with Jules van Binsbergen, Menachem Brenner, Stephen Brown, George Constantinides, Zhi Da, Wayne Ferson, Mark Grinblatt, Arthur Korteweg, Tyler Shumway, Aurelio Vasquez, Peter Wakker, Robert Whitelaw, Jeffrey Wurgler, and Hao Zhou. We also thank Nusret Cakici (the referee), Paul Malatesta (the editor), and conference participants and discussants at the 2012 Eastern Finance Association Meeting, the 2012 European Finance Association Meeting, the 2013 American Finance Association Meeting, and the 2013 Luxembourg Asset Management Summit. Baltussen and van Bekkum gratefully acknowledge financial support from the Tinbergen Institute, the Erasmus Research Institute of Management, and the Erasmus Trustfonds. van Bekkum also gratefully acknowledges financial support from the Niels Stensen Foundation. Part of this research project was completed when either Baltussen or van Bekkum was at New York University.

${ }^{1}$ For instance, a security's volatility (rather than its covariance with the market) plays a "central role in its equilibrium price determination" in a capital asset pricing model (CAPM) world with transaction
} 
In this article, we propose that it is not just the volatility characteristic that determines stock returns but also uncertainty about volatility. The impact of such uncertainty about risk on individual stock returns matters if volatility shapes the probability distribution of returns, and investors differently evaluate a stock yielding a certain payoff with probability $\pi$ and a stock yielding the same payoff but with an uncertain probability whose expectation is $\pi$. This idea can be traced back to an important strand of literature initiated by Segal (1987) arguing that when $\pi$ is uncertain, an investor may order her expectations in 2 stages. The first stage is over the possible values of parameters that shape the returns distribution (e.g., mean and variance), and the second stage is over future stock returns drawn from this distribution. Considering that volatility strongly affects the probability distribution of returns, uncertainty about volatility is likely to be such a first-stage parameter. Although the literature is too extensive to cover here, a small selection of papers also demonstrating that 2-stage utility represents decision making includes Segal (1990), Nau (2003), (2006), Klibanoff, Marinacci, and Mukerji (2005), Ergin and Gul (2009), Seo (2009), Neilson (2010), and Conte and Hey (2013). Critically, uncertainty about risk enters an investor's utility function and could therefore affect stock returns.

We empirically measure uncertainty about risk by the volatility of expected volatility (vol-of-vol) and find that stocks with a higher vol-of-vol characteristic earn significantly lower future returns than otherwise similar stocks in our sample from 1996 to 2014. When we sort stocks into value-weighted (equalweighted) quintile portfolios, stocks in the highest vol-of-vol quintile underperform stocks in the lowest vol-of-vol quintile by $0.69 \%(0.50 \%)$ in the month following portfolio formation, equivalent to about $8 \%(6 \%)$ per year. This negative vol-of-vol effect is not explained by loadings on the market, the Fama-French (1993) size and book-to-market factors, or the Carhart (1997) momentum factor, with a 4-factor alpha of $-0.60 \%(-0.44 \%)$ a month for the high-minus-low value-weighted (equal-weighted) vol-of-vol portfolio. Importantly, this holds in our sample that is by construction tilted to the larger, more liquid, and economically most relevant stocks. Portfolio sorts and Fama-MacBeth (1973) regressions indicate that this vol-of-vol effect is distinct from more than 20 previously documented return drivers, and robust. It persists up to 24 months after portfolio formation, holds for a variety of vol-of-vol definitions, is not driven by specific events during our sample period, and survives several more robustness checks. Furthermore, the vol-of-vol effect is also strongly present in Europe, with an annualized high-minus-low return of nearly $6 \%$ per year.

costs and indivisible assets (Levy (1978)). In his American Finance Association presidential address, Merton (1987) demonstrates in a similar setup that volatility also affects expected returns because of idiosyncratic risk when investors can only follow a subset of stocks or when information is incomplete. Shleifer and Vishny (1997) argue that the volatility characteristic could affect stock returns because idiosyncratic risk reflects limits to arbitrage. Furthermore, volatility may be priced as a consequence of several empirical findings: nonconcave "market" utility functions (see Post and Levy (2005)), concerns about fluctuations in individual stocks rather than total portfolios (Barberis and Huang (2001), Baltussen and Post (2011)), or underdiversification (Goetzmann and Kumar (2005), Polkovnichenko (2005)). 
We explicitly distinguish between vol-of-vol as a stock-level factor or characteristic, as the vol-of-vol effect may arise because exposures to an aggregate vol-of-vol factor, rather than to individual stock vol-of-vol factors, are priced. For example, exposures to vol-of-vol might be priced in a factor model, as in Ross's (1976) arbitrage pricing theory, or if vol-of-vol provides a hedge against deteriorating investment opportunities (Campbell (1993), (1996), Ang, Hodrick, et al. (2006)). We formally test whether exposures to market-level vol-of-vol are priced and whether the lower returns predicted by a vol-of-vol characteristic reflect a priced vol-of-vol factor in traditional asset pricing models, but we cannot confirm this econometrically. Vol-of-vol seems primarily priced as a characteristic and appears distinctly different from factor-based explanations.

Although our main focus is on establishing the vol-of-vol effect, we also explore why uncertainty about risk is primarily priced negatively. A possible explanation for the negative effect of uncertainty about risk on future stock returns is that investors have a structural preference for uncertainty about risk. Another explanation is that if investors' uncertainty about risk preferences or expectations are sufficiently dispersed and uncertainty about risk sufficiently large, investors with relatively high uncertainty aversion and/or pessimistic uncertainty expectations may cease participating in a stock. As a consequence, the uncertain assets are held, and priced, only by investors with a sufficiently optimistic view on (or low aversion against) uncertainty, and therefore require low uncertainty premiums. This "limited participation" phenomenon is linked theoretically to lower stock prices in prior work (e.g., Cao, Wang, and Zhang (2005), Chapman and Polkovnichenko (2009), and Bossaerts, Ghirardato, Guarnaschelli, and Zame (2010)), ${ }^{2}$ and its mechanism is similar to the idea that negative returns arise when the most pessimistic investors are kept out of the market because of short-sale constraints (Miller (1977)). We present empirical evidence in line with this idea, as stocks with higher levels of uncertainty about risk are also associated with lower future trading activity, and larger future decreases in trading activity.

Prior work offers several other interpretations for the negative link between vol-of-vol and stock returns, yet we find that none can offer a satisfactory explanation. First, the impact of vol-of-vol on stock returns might simply capture compensation for stochastic volatility risk or jump risk (see Bakshi and Kapadia (2003), Bali and Hovakimian (2009), and Cremers, Halling, and Weinbaum (2015)). However, the vol-of-vol effect remains economically and statistically significant after controlling for stock-level variation in implied volatility (IV) (An, Ang, Bali, and Cakici (2014)), stock-level variance risk premiums (Bali and Hovakimian (2009)), or stock-level exposure to aggregate jump risk and volatility

\footnotetext{
${ }^{2}$ Chapman and Polkovnichenko (2009) show theoretically that the premium for uncertainty decreases when agents differ sufficiently in their uncertainty aversion, and using similar arguments, Cao et al. (2005) show that limited participation can lead to a lower equity premium when investors are heterogeneous in their uncertainty preferences. Similarly, Uppal and Wang (2003) show that uncertaintyaverse agents hold less diversified portfolios because investors shy away from assets they feel more uncertain about. Experimental evidence also points toward heterogeneous uncertainty preferences and beliefs (Ahn, Choi, Gale, and Kariv (2014), Halevy (2007), Cubitt, van de Kuilen, and Mukerji (2012), and Conte and Hey (2013)) and reveals a significant relation between uncertainty and participation in asset markets (Bossaerts et al. (2010)).
} 
risk (Cremers et al. (2015)). Alternatively, vol-of-vol in part follows the quarterly earnings cycle, suggesting that earnings announcements are accompanied by increased vol-of-vol, and the vol-of-vol effect might relate to previously documented earnings anomalies. However, we find that the vol-of-vol effect is present in stock-month observations regardless of whether earnings are reported, persists after deseasonalizing our measure for vol-of-vol, and is not explained by postearnings-announcement drift. The vol-of-vol effect may also be caused by optimism bias, with high vol-of-vol stocks indicating further deviations from fundamental value than low vol-of-vol stocks. However, the vol-of-vol effect persists after controlling for short-sale constraints, does not vary significantly for different levels of short-sale constraints, and is not stronger when arbitrage risk is higher. Vol-of-vol might also capture higher moments that indicate (potentially asymmetric) risks not captured in measures for idiosyncratic volatility, beta, skewness, or kurtosis. However, after studying the future returns distribution of vol-of-vol portfolios, we find no evidence for these explanations.

\section{Vol-of-Vol Measure and Data}

We measure uncertainty about risk by calculating the vol-of-vol from IVs derived from option prices. IV is primarily driven by expected stock price volatility, is one of the best predictors of volatility, and hence measures the future stock return volatility expected by investors. The volatility of IV, then, captures the uncertainty in investors' assessments of these risks. The main advantage of using option market information is that option prices are forward looking by nature, making them an appealing basis to measure investors' uncertainty about risk ex ante. In addition, options are written on the stock itself, traded by a large number of agents, and observed on a daily frequency. Hence, unlike, for example, earnings estimated by analysts or survey forecasts by other investment professionals, expectations are extracted from actual financial market transactions. Being derived directly from market prices also circumvents self-selection problems and optimism bias in analyst forecasts (e.g., McNichols and O'Brien (1997)), and prevents distortions by incentive-related effects.

Because the absolute changes in IV tend to be larger for high-volatility stocks than for low-volatility stocks, we filter the effect of the level of expected risk from our measure of uncertainty about risk by scaling the standard deviation of IV of stock $i$ on day $t\left(\sigma_{i, t}^{\mathrm{IV}}\right)$ with the average IV over the past month $\left(\bar{\sigma}_{i, t}^{\mathrm{IV}}\right)$. Thus, we calculate the vol-of-vol for stock $i$ on day $t$ as follows:

$$
\mathrm{VOV}_{i, t}^{1 \mathrm{M}}=\frac{\sqrt{\frac{1}{20} \sum_{j=t-19}^{t}\left(\sigma_{i, j}^{\mathrm{IV}}-\bar{\sigma}_{i, t}^{\mathrm{IV}}\right)^{2}}}{\bar{\sigma}_{i, t}^{\mathrm{IV}}},
$$

where $\bar{\sigma}_{i, t}^{\mathrm{IV}}=(1 / 20) \sum_{j=t-19}^{t} \sigma_{i, j}^{\mathrm{IV}}$, and $\sigma_{i, j}^{\mathrm{IV}}$ is implied volatility.

At first glance, one would be tempted to calculate vol-of-vol over the crosssectional variation in IVs from the different options that are written on the 
same stock. However, although this would closely follow the literature on forecast dispersion, such cross-sectional variation in IV would not be comparable across stocks as it would be primarily driven by differences in option moneyness and time to maturity. Therefore, we measure vol-of-vol as the time variation in daily IV, with IV measured as the average IV of the call option and put option that are closest to being at the money (ATM). Such ATM IV quotes are generally based on the most liquid, actual option prices. We calculate vol-of-vol at the same (i.e., monthly) horizon as we calculate stock returns, to balance the precision of our vol-of-vol estimates against sufficient time variation in vol-of-vol that is up to date. We require at least 12 nonmissing observations to compute vol-of-vol. We also delete vol-of-vol values that are not available for more than 10 days. In the Internet Appendix (available at www.jfqa.org), we verify that the results are similar when we do not scale vol-of-vol and log-transform vol-of-vol, or when we implicitly assume a random walk and measure vol-of-vol in first differences rather than levels. ${ }^{3}$

We use data of U.S.-listed options that are written on individual stocks trading on the New York Stock Exchange (NYSE), American Stock Exchange (AMEX), and National Association of Securities Dealers Automated Quotation (NASDAQ) (all of which are American). From OptionMetrics we obtain daily IVs, closing bid and ask prices, option strikes and maturities, as well as information on options' volume and open interest. The option data run from Jan. 1, 1996 (the first date in the OptionMetrics database) until Sept. 30, 2014. We use these data to analyze future returns from Feb. 1996 until Oct. 2014 (for monthly returns) or Dec. 2014 (for longer horizons). In Section A of the Internet Appendix, we describe in more detail our choices and filters applied to the OptionMetrics data.

Stock prices and returns data are obtained from the Center for Research in Security Prices (CRSP). We select all data for ordinary common shares (CRSP share codes 10 and 11) listed on the NYSE, AMEX, and NASDAQ, and exclude closed-end funds and real estate investment trusts (REITs) (Standard Industrial Classification (SIC) codes 6720-6730 and 6798). Accounting data are obtained from Compustat. Analyst forecasts, dispersion, and revision data are from Thomson Reuters Institutional Brokers' Estimate System (IBES). For IBES, the U.S. unadjusted file is used to mitigate the problem of imprecise forecasts (Diether, Malloy, and Scherbina (2002)). Data on institutional ownership are from the Thomson Reuters 13F database, and we use Kenneth French's online data library (http://mba.tuck.dartmouth.edu/pages/faculty/ken.french/data_library.html) to obtain the risk-free rate, market, size, value, and momentum factors. In Section B of the Internet Appendix, we describe in detail the data filters we apply to these data sets. We match OptionMetrics data to monthly CRSP data using the procedure outlined by Duarte, Lou, and Sadka (2005), and select option data on the last-but-one trading day of a month to match to stock returns over the next month(s). This 1-day implementation lag avoids spurious findings caused by nonsynchronous trading between options and stocks due to slightly different

${ }^{3}$ Furthermore, our results are comparable if we require fewer or more nonmissing observations, do not correct for unavailable observations, or measure vol-of-vol over longer windows. 
closing times of the exchanges (Battalio and Schultz (2006)), and takes into account the time needed for less technologically advanced investors to process the option information.

Panel A of Table 1 provides an overview of our sample relative to the CRSP universe. A substantial number of stocks satisfy our screening criteria, and firms with sufficient OptionMetrics data tend to have stocks with larger market capitalization. In the first year that OptionMetrics data are available, $26 \%$ of the firms in our CRSP universe have sufficient listed option data available, and this increases to about $40 \%$ in the last years of our sample. The stocks represent $69 \%-90 \%$ of market capitalization of stocks included in our CRSP universe, indicating that larger firms tend to have well-traded options listed on their stocks. Hence, our sample is tilted toward larger stocks that are generally better tracked and more investable.

Panel B of Table 1 presents summary statistics for vol-of-vol for each year in our sample. The statistics are computed by first value weighing vol-of-vol each month for each firm, and then averaging per year. The average vol-of-vol level indicates that risk uncertainty about risk tends to increase during turbulent market years such as 2001 and 2007-2008, and has stayed above average in recent years. Moreover, vol-of-vol varies substantially across firms, with an average standard deviation of about $6 \%$.

\section{Is Vol-of-Vol a Priced Stock Characteristic?}

To examine whether vol-of-vol is priced, we start with the ranking of all stocks in ascending order based on vol-of-vol at the end of month $t$ (taking into account a 1-day implementation lag). We then sort the stocks into quintile portfolios. The first portfolio (low) contains stocks with the lowest vol-of-vol values, and the fifth portfolio (high) contains stocks with the highest vol-of-vol values.

\section{A. What Explains Vol-of-Vol?}

To examine what it is that distinguishes high vol-of-vol stocks from low vol-of-vol stocks, Table 2 shows how several stock characteristics vary across the vol-of-vol quintiles. For the sake of brevity, we define the stock characteristics in the Appendix and do not motivate and discuss them all individually. For each month and each quintile, we compute value-weighted averages of the stock characteristics at portfolio formation (except for size, which is computed on an equal-weighted basis). Next, we compute the time-series average and NeweyWest (1987) adjusted $t$-statistic over all months in our sample. The top row reports the average vol-of-vol around portfolio formation.

\section{Vol-of-Vol and Previously Documented Measures of Risk and Uncertainty}

We may expect vol-of-vol to relate positively to measures of risk or other forms of uncertainty. Table 1 shows that as vol-of-vol increases across the quintiles, so do many variables that capture some dimension of risk or uncertainty. For instance, high vol-of-vol stocks have higher beta (BETA) and are characterized by higher idiosyncratic volatility (IDIOSYNC_VOLATILITY), higher past-month maximum returns (MAXIMUM_RETURN), and a more 
TABLE 1

Descriptive Statistics Vol-of-Vol Sample

Table 1 reports descriptive statistics for vol-of-vol over our sample period from Jan. 1996 to Oct. 2014. Vol-of-vol is past month's volatility of option-implied volatility (IV), standardized by average IV (see Section II). IV is calculated from at-themoney call and put options with maturity closest to 30 days. Panel A reports the coverage statistics for our sample versus the Center for Research in Security Prices (CRSP) sample. The first 3 data columns show the number of CRSP stocks included in our analysis ("No. of Stocks"), the number of CRSP stocks for which we could compute our vol-of-vol measure ("No. of Stocks with Vol-of-Vol"), and the number of stocks for which we could compute vol-of-vol as a percentage of the number of CRSP stocks ("Pct. of Stocks with Vol-of-Vol"). The last 3 columns show the average market capitalization of CRSP stocks ("MV of Stocks (\$mil)"), the stocks for which we can compute vol-of-vol ("MV of Stocks with Vol-of-Vol (\$mil)"), and the stocks for which we can compute vol-of-vol as a percentage of the total market capitalization of CRSP stocks ("MV of Stocks with Vol-of-Vol (\%)"). Panel B reports year-by-year summary statistics for vol-of-vol. It presents the sample averages of the monthly value-weighted mean, standard deviation, and 25th, 50th, and 75th percentiles of vol-of-vol, grouped by year. The bottom row shows the grand average over our total sample.

Panel A. Coverage Statistics

\begin{tabular}{|c|c|c|c|c|c|c|}
\hline Year & $\begin{array}{l}\text { No. of } \\
\text { Stocks }\end{array}$ & $\begin{array}{c}\text { No. of } \\
\text { Stocks } \\
\text { with } \\
\text { Vol-of-Vol }\end{array}$ & $\begin{array}{c}\text { Pct. of } \\
\text { Stocks } \\
\text { with } \\
\text { Vol-of-Vol }\end{array}$ & $\begin{array}{l}\text { MV of } \\
\text { Stocks } \\
\text { (\$mil) }\end{array}$ & $\begin{array}{c}\text { MV of } \\
\text { Stocks } \\
\text { with } \\
\text { Vol-of-Vol } \\
\text { (\$mil) }\end{array}$ & $\begin{array}{c}\text { MV of } \\
\text { Stocks } \\
\text { with } \\
\text { Vol-of-Vol } \\
(\%)\end{array}$ \\
\hline 1996 & 3,414 & 898 & $26 \%$ & 1,975 & 5,326 & $69 \%$ \\
\hline 1997 & 3,583 & 1,241 & $35 \%$ & 2,398 & 5,739 & $81 \%$ \\
\hline 1998 & 3,498 & 1,382 & $39 \%$ & 3,046 & 6,689 & $85 \%$ \\
\hline 1999 & 3,213 & 1,376 & $43 \%$ & 4,047 & 8,386 & $88 \%$ \\
\hline 2000 & 3,172 & 1,341 & $42 \%$ & 4,867 & 10,227 & $88 \%$ \\
\hline 2001 & 2,700 & 1,155 & $43 \%$ & 4,741 & 9,741 & $87 \%$ \\
\hline 2002 & 2,476 & 1,071 & $43 \%$ & 4,441 & 8,774 & $84 \%$ \\
\hline 2003 & 2,485 & 971 & $39 \%$ & 4,242 & 9,062 & $82 \%$ \\
\hline 2004 & 2,793 & 1,128 & $40 \%$ & 4,600 & 9,720 & $84 \%$ \\
\hline 2005 & 2,832 & 1,167 & $41 \%$ & 4,930 & 10,263 & $84 \%$ \\
\hline 2006 & 2,889 & 1,270 & $44 \%$ & 5,219 & 10,323 & $86 \%$ \\
\hline 2007 & 2,847 & 1,360 & $48 \%$ & 5,853 & 10,793 & $87 \%$ \\
\hline 2008 & 2,365 & 1,147 & $49 \%$ & 5,838 & 10,513 & $86 \%$ \\
\hline 2009 & 2,187 & 946 & $43 \%$ & 4,595 & 9,217 & $86 \%$ \\
\hline 2010 & 2,843 & 1,106 & $39 \%$ & 4,335 & 9,953 & $88 \%$ \\
\hline 2011 & 2,808 & 1,084 & $39 \%$ & 5,088 & 11,792 & $88 \%$ \\
\hline 2012 & 2,740 & 1,065 & $39 \%$ & 5,448 & 12,622 & $89 \%$ \\
\hline 2013 & 2,848 & 1,211 & $43 \%$ & 6,196 & 13,235 & $90 \%$ \\
\hline 2014 & 3,000 & 1,225 & $41 \%$ & 6,997 & 15,225 & $88 \%$ \\
\hline
\end{tabular}

Panel B. Summary Statistics of Vol-of-Vol

\begin{tabular}{|c|c|c|c|c|c|}
\hline \multirow[b]{2}{*}{ Year } & \multirow[b]{2}{*}{ Mean } & \multirow[b]{2}{*}{ Std. Dev. } & \multicolumn{3}{|c|}{ Percentile } \\
\hline & & & 25th & 50th & 75th \\
\hline 1996 & $9.27 \%$ & $6.43 \%$ & $5.27 \%$ & $7.80 \%$ & $11.40 \%$ \\
\hline 1997 & $8.95 \%$ & $6.83 \%$ & $4.76 \%$ & $7.22 \%$ & $10.83 \%$ \\
\hline 1998 & $9.04 \%$ & $6.43 \%$ & $5.04 \%$ & $7.49 \%$ & $11.15 \%$ \\
\hline 1999 & $8.28 \%$ & $6.21 \%$ & $4.09 \%$ & $6.19 \%$ & $9.39 \%$ \\
\hline 2000 & $7.90 \%$ & $6.33 \%$ & $4.27 \%$ & $6.54 \%$ & $9.93 \%$ \\
\hline 2001 & $8.66 \%$ & $5.55 \%$ & $5.15 \%$ & $7.48 \%$ & $10.68 \%$ \\
\hline 2002 & $9.14 \%$ & $5.56 \%$ & $5.48 \%$ & $7.97 \%$ & $11.32 \%$ \\
\hline 2003 & $8.45 \%$ & $4.96 \%$ & $5.39 \%$ & $7.46 \%$ & $10.23 \%$ \\
\hline 2004 & $8.24 \%$ & $5.56 \%$ & $5.11 \%$ & $7.06 \%$ & $9.84 \%$ \\
\hline 2005 & $8.55 \%$ & $5.51 \%$ & $5.21 \%$ & $7.29 \%$ & $10.36 \%$ \\
\hline 2006 & $8.84 \%$ & $6.00 \%$ & $5.38 \%$ & $7.42 \%$ & $10.42 \%$ \\
\hline 2007 & $9.39 \%$ & $6.15 \%$ & $6.05 \%$ & $8.17 \%$ & $11.31 \%$ \\
\hline 2008 & $9.93 \%$ & $5.61 \%$ & $7.19 \%$ & $9.47 \%$ & $12.56 \%$ \\
\hline 2009 & $8.56 \%$ & $4.87 \%$ & $5.62 \%$ & $7.58 \%$ & $10.36 \%$ \\
\hline 2010 & $9.02 \%$ & $5.49 \%$ & $5.80 \%$ & $7.97 \%$ & $10.95 \%$ \\
\hline 2011 & $9.71 \%$ & $5.68 \%$ & $6.30 \%$ & $8.47 \%$ & $11.58 \%$ \\
\hline 2012 & $9.97 \%$ & $5.82 \%$ & $6.61 \%$ & $8.84 \%$ & $11.77 \%$ \\
\hline 2013 & $9.75 \%$ & $6.95 \%$ & $5.78 \%$ & $8.20 \%$ & $11.93 \%$ \\
\hline 2014 & $9.94 \%$ & $7.33 \%$ & $5.76 \%$ & $8.46 \%$ & $12.33 \%$ \\
\hline Avg. & $9.03 \%$ & $5.96 \%$ & $5.49 \%$ & $7.74 \%$ & $10.97 \%$ \\
\hline
\end{tabular}

positively skewed (SKEWNESS) and leptokurtic (KURTOSIS) return distribution. Furthermore, the volatility skew (OTM_SKEW) increases with vol-of-vol, suggesting that stocks surrounded with more uncertainty about risk raise concerns about downside risk. Vol-of-vol relates negatively to the spread between IV and 
TABLE 2

\section{Stock Characteristics of Portfolios Sorted by Vol-of-Vol}

Table 2 reports how vol-of-vol relates to other stock-level characteristics. The table presents average characteristics for portfolios sorted by vol-of-vol over our sample period from Jan. 1996 to Oct. 2014. Vol-of-vol is past month's volatility of option-implied volatility (IV), standardized by average IV (see Section II). IV is calculated from at-the-money call and put options with maturity closest to 30 days. Each month we sort stocks in ascending order into quintile portfolios ("Low," "2," "3," " 4 ," and "High") on the basis of vol-of-vol. We use a 1-trading-day implementation lag and value weigh stocks in each portfolio (except for size, which is equal weighted). The table presents average characteristics at the end of month, as well as the difference in means between portfolio high and portfolio low ("High-Low"). The top row ("VOL_OF_VOL") shows the average vol-of-vol in each portfolio. Subsequent rows present averages for stock characteristics, each of which is defined in the Appendix except those in Panel G, which are defined in Section III.A. We report the Newey-West (1987) corrected $t$-statistics in parentheses. ${ }^{* *}$ and ${ }^{* * *}$ indicate significance at the $5 \%$ and $1 \%$ levels, respectively.

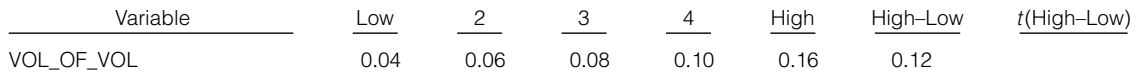

Panel A. Canonical Characteristics

BETA

BOOK_TO_MARKET

SIZE (in \$billions)

MOMENTUM

$\begin{array}{ll}0.98 & 0.98 \\ 0.41 & 0.39\end{array}$

SHORT_TERM_REVERSA

7.78

3.79

0.39
10.48

3.01

3.10

0.39

11.04

2.64

2.64
3.16

0.39

11.18

2.13

3.23

1.02

0.40
8.60

1.16

4.39

$0.04^{\star *}$

$-0.01$

$0.82^{\star \star}$

$-2.63^{\star \star \star}$

1.38

(2.42)

$(-0.98)$

(2.12)

$(-3.95)$

Panel B. Returns Distribution Characteristics

IDIOSYNC_VOLATILITY (\%)
MAXIMUM_RETURN (\%)
SKEWNESS

SKEWNESS

$1.71 \quad 1.63$

$\begin{array}{ll}1.71 & 1.63 \\ 4.06 & 4.02\end{array}$

$0.13 \quad 0.10$

1.62

1.64

1.75

$0.04^{\star *}$

$1.10^{\star \star \star}$

$0.13-0.10$

5.16
0.20

$0.07^{\star \star *}$

5.78

$2.14^{\star \star \star}$

(2.00)

(10.95)

(5.31)

Graph C. Liquidity Characteristics

TURNOVER

Panel D. Option-Based Characteristics

0.02

$0.21^{\star \star \star}$

ATM_SKEW (\%)

OTM_SKEW (\%)

IV_RV_SPREAD (\%)

$\triangle$ CALL_IV $(\%)$

0.17

0.16

0.16

$-0.37$

4.13

0.65

$-0.04$

$\triangle$ PUT_IV $(\%)$

$3.79 \quad 3.93$

$2.07 \quad 1.18$

0.08

0.08

0.05

$-0.04$

\subsection{6}

$-0.36$

4.25

0.19

$-0.16$

0.02

0.18

0.01

0.18

$0.66^{\star \star \star}$

4.46

$-1.63$

$-0.33$

$-3.70^{\star *}$

$-0.41$

$-0.47$

Panel E. Uncertainty-Related Characteristics

AGE

ANALYST_COVERAGE

$34.70 \quad 38.92$

38.61

37.59

33.76

$-0.94$

$(-1.32)$

20.89

0.22

20.29

0.25

$0.75^{\star \star *}$

$0.02^{\star \star}$

$1.32^{\star \star \star *}$

(3.01)

(2.24)

(5.61)

$0.55-0.01$

$(-0.82)$

PRIVATE_INFORMATION

\begin{tabular}{|c|}
\hline D \\
\hline
\end{tabular}

33.84
0.51

$(-0.53)$

$(0.00)$

$(-3.91)$

\subsection{8}

0.24

0.58

0.22
0.31

0.58
0.22

0.58

0.21
0.33

0.57
0.24

0.00

0.00

Panel G. Characteristics Further Explaining VOL_OF_VOL

$\begin{array}{lrrr}\text { VOL_OF_VOL_AT_TIME_( } t-1) & 0.08 & 0.08 & 0.08 \\ \text { (MONTHLY_RETURN) }^{2} & 7.99 & 8.29 & 9.90 \\ \text { ASTOCK_TURNOVER (\%) } & -8.77 & -5.44 & -2.46 \\ \text { DOPTION_VOLUME (\%) } & -9.86 & -4.02 & 0.40 \\ \text { STDEV_OPTION_BID_ASK (\%) } & 3.51 & 3.48 & 3.50 \\ \text { PAST_QUARTERS_SUE (\%) } & 0.14 & 0.09 & 0.06 \\ \text { EARN_REP_MONTH (0/1) } & 24.18 & 27.47 & 30.88 \\ \text { RD/ASSETS (\%) } & 4.97 & 4.81 & 5.05 \\ \text { PPE/ASSETS (\%) } & 54.89 & 54.07 & 50.3 \\ \text { SALES_GROWTH (\%) } & 15.04 & 16.61 & 15.8\end{array}$

$\begin{array}{rrrr}0.09 & 0.10 & 0.02^{\star \star \star} & (15.98) \\ 10.83 & 15.30 & 7.31^{\text {}} & (4.67) \\ 2.38 & 17.07 & 25.84^{\star \star \star} & (18.33) \\ 5.64 & 20.92 & 30.77^{\star \star \star} & (23.37) \\ 3.73 & 4.93 & 1.42^{\star \star \star} & (7.16) \\ 0.13 & 0.12 & -0.01 & (-0.24) \\ 34.72 & 43.59 & 19.41^{\star \star \star} & (11.42) \\ 5.14 & 5.63 & 0.67^{\star \star \star} & (3.98) \\ 48.45 & 45.03 & -9.86^{\star \star \star} & (-10.42) \\ 11.39 & 10.47 & -4.57 & (-0.66)\end{array}$

historical, realized volatility (IV_RV_SPREAD) ${ }^{4}$ Turning to other uncertaintyrelated characteristics, high vol-of-vol stocks have higher forecast dispersion

${ }^{4}$ This suggests that stocks with volatile volatility are less exposed to negatively priced volatility risk. We discuss this relation in more detail in Section VI.A. 
(FORECAST_DISPERSION) and higher total volatility (VOLATILITY), which indicate higher information uncertainty (Zhang (2006)) and analyst disagreement (Diether et al. (2002)). By contrast, high vol-of-vol stocks have higher analyst coverage, indicating less information uncertainty as in Zhang (2006). Collectively, the results in this section show that vol-of-vol tends to be positively related to many previously documented forms of risk and uncertainty.

In correlation analyses and regressions of vol-of-vol on these characteristics (unreported), we confirm the relation between vol-of-vol and the previously documented proxies for uncertainty. However, $R^{2}$ averages to a maximum of about $15 \%$, indicating that vol-of-vol also captures a distinct part of uncertainty that is not reflected in previously proposed measures.

\section{Vol-of-Vol and Measures of Information Arrival}

In Panel $\mathrm{G}$ of Table 2, we examine to what extent vol-of-vol is explained by several other variables that are not examined in the literature but that can provide further insight into what drives uncertainty about risk. First, the rows labeled "Vol-of-vol at time $t-1$ " suggest that uncertainty about risk does not vanish from one month to the next. Uncertainty about risk is a relatively persistent stock characteristic.

Next, we expect uncertainty about risk to change when material new information arrives at investors, as this can trigger investors to update their beliefs about the level of and uncertainty about risk. Such information could be reflected in extremely positive or extremely negative changes in the share price that we capture by squared stock returns over the last month. The row labeled "(MONTHLY_RETURN $)^{2}$ " shows that vol-of-vol significantly increases with such extreme stock price movements. ${ }^{5}$ Furthermore, the arrival of material information is likely to lead to increased stock and option trading activity and higher variation in trading costs in the options markets. We proxy this by contemporaneous changes in stock turnover and in option trading volume, and by the 1-month volatility of the option bid-ask spread. All these characteristics do indeed increase monotonically and significantly over the vol-of-vol quintiles. Similarly, material new information is likely to arrive during earnings announcement months. Because the level of uncertainty might especially increase when realized earnings deviate from earnings expectations, we also examine how vol-of-vol changes with standardized earnings surprises (SUEs) over the previous quarter. Although earnings surprises do not increase with vol-of-vol, vol-of-vol is strongly related to a dummy variable indicating whether a stock has reported earnings in the past month. ${ }^{6}$

\footnotetext{
${ }^{5}$ In this sense, (MONTHLY_RETURN) ${ }^{2}$ relates to the gamma effect in (monthly) option returns (i.e., the sensitivity of option prices to extreme stock price changes). The links between vol-of-vol and the 2 other key option return drivers, change in volatility and change in stock prices, are less important. This can be observed from other panels in Table 2. More specifically, the monthly change in the share price (SHORT_TERM_REVERSAL) is the main driver behind the option delta effect in option returns (i.e., the sensitivity of option prices to price changes in the underlying stock). Similarly, monthly changes in call IV and monthly changes in put IV capture the vega effect in option returns (i.e., the sensitivity of put and call option prices to changes in volatility).

${ }^{6}$ We thank Zhi Da for first observing this.
} 
Finally, we may expect uncertainty about risk to be positively related to characteristics that reflect more uncertain company-level prospects. In line with this conjecture, we find that higher vol-of-vol firms tend to have higher research and development (R\&D) (as a proportion of total assets) and less tangible capital (measured by property, plant, and equipment (PPE) over total assets). Conversely, vol-of-vol is not significantly related to sales growth over the previous year, which is often used to proxy for growth opportunities. Collectively, these results indicate that uncertainty about risk is higher when new information arrives and when firms have more uncertain company-level prospects.

Although many of these measures are highly significant, the regressions (unreported) of vol-of-vol on all characteristics discussed previously yield an $R^{2}$ of about $35 \%$, indicating that vol-of-vol also captures a distinctly different part of uncertainty about risk that is not reflected in these measures.

\section{B. Vol-of-Vol Effect}

We continue by computing, for each of the 5 vol-of-vol portfolios, the valueweighted and equal-weighted return over the following month. We then form a high-low vol-of-vol portfolio that buys the high vol-of-vol portfolio and sells the low vol-of-vol portfolio. This position is held for 1 month. For each quintile and high-low portfolio, Table 3 reports time-series averages of the cross-sectional average vol-of-vol (rows labeled "Vol-of-vol"), average excess returns ("Excess return"), and intercepts from the regression of excess portfolio returns on: i) a constant and the excess market return ("CAPM alpha"), ii) the previous model augmented by the size and value factors as in Fama and French (1993) ("3F alpha"), and iii) the previous model augmented by the momentum factor following Carhart (1997) (“4F alpha”).

\section{Value-Weighted Portfolios}

Panel A of Table 3 contains the results after value-weighting stocks within each portfolio. During our sample period, low vol-of-vol stocks earn on average $0.81 \%$ per month in excess of the risk-free rate, whereas high vol-of-vol stocks earn $0.12 \%$. The difference as implemented in the high-low portfolio equals an economically large $-0.69 \%$ per month, with a highly significant $t$-statistic of -2.96. A similar significant negative performance is observed for the alphas in the CAPM and 3-factor Fama-French (1993) model, indicating that the market, value, and size factors do not drive the return spread on the high-low vol-of-vol portfolio. Similarly, the alpha in the 4-factor regression is economically substantial, with a high-low differential of $-0.60 \%$ per month and a significant $t$-value of -2.62 . This indicates that vol-of-vol is also distinct from exposures associated with momentum. Alphas are highly significant for the high vol-of-vol quintile, suggesting that the vol-of-vol effect is partly driven by the short side. This is further investigated in Section VI.C. Graph A of Figure 1 graphically illustrates the vol-of-vol effect. Portfolio returns decrease almost monotonically from quintile 1 (low) to quintile 5 (high).

\section{Equal-Weighted Portfolios}

The results for equal-weighted portfolios, presented in Panel B of Table 3 , also reveal an economically important and statistically significant negative 
TABLE 3

Returns on Portfolios Sorted by Vol-of-Vol

Table 3 reports average monthly returns on portfolios sorted by vol-of-vol over our sample period from Jan. 1996 to Oct. 2014. Vol-of-vol is past month's volatility of option-implied volatility (IV), standardized by average IV (see Section II). IV is calculated from at-the-money call and put options with maturity closest to 30 days. Each month we sort stocks in ascending order into quintile portfolios ("Low," "2," "3," "4," and "High") on the basis of vol-of-vol. We use a 1-trading day implementation lag. The table presents average returns and alphas for each portfolio over the subsequent month, as well as the difference in monthly returns or alphas between the high portfolio and the low portfolio ("High-Low"). The top row ("Vol-of-vol") shows the average vol-of-vol of each portfolio. The remaining rows present excess returns ("Excess return") and alphas from the Sharpe (1964)-Lintner (1965) model ("CAPM alpha"), from the Fama-French (1993) 3-factor model ("3F alpha"), and from the Fama-French (1993)-Carhart (1997) 4-factor model ("4F alpha"). Panel A presents results for value-weighted portfolios, and Panel B for equal-weighted portfolios. Panel $\mathrm{C}$ tabulates each portfolio's average number of stocks per month and the fraction of stocks that remain in the same portfolio from one month to the next. We report the Newey-West (1987) corrected $t$-values in parentheses. ${ }^{*},{ }^{* *}$, and ${ }^{* \star *}$ indicate significance at the $10 \%, 5 \%$, and $1 \%$ levels, respectively.

\begin{tabular}{|c|c|c|c|c|c|c|}
\hline Statistics & Low & 2 & 3 & 4 & High & High-Low \\
\hline \multicolumn{7}{|l|}{$\underline{\text { Panel A. Value-Weighted Returns }}$} \\
\hline Vol-of-vol & 0.04 & 0.06 & 0.08 & 0.10 & 0.16 & 0.12 \\
\hline Excess return & $\begin{array}{l}0.81^{\star \star \star} \\
(2.61)\end{array}$ & $\begin{array}{l}0.61^{\star \star} \\
(1.99)\end{array}$ & $\begin{array}{l}0.68^{* *} \\
(2.06)\end{array}$ & $\begin{array}{c}0.40 \\
(1.19)\end{array}$ & $\begin{array}{c}0.12 \\
(0.32)\end{array}$ & $\begin{array}{l}-0.69^{* * *} \\
(-2.96)\end{array}$ \\
\hline CAPM alpha & $\begin{array}{l}0.29^{* \star} \\
(2.31)\end{array}$ & $\begin{array}{c}0.08 \\
(0.78)\end{array}$ & $\begin{array}{c}0.11 \\
(1.25)\end{array}$ & $\begin{array}{c}-0.18^{*} \\
(-1.81)\end{array}$ & $\begin{array}{l}-0.52^{\star \star \star} \\
(-3.59)\end{array}$ & $\begin{array}{l}-0.81^{* * *} \\
(-3.37)\end{array}$ \\
\hline 3F alpha & $\begin{array}{l}0.24^{\star \star} \\
(2.13)\end{array}$ & $\begin{array}{c}0.07 \\
(0.71)\end{array}$ & $\begin{array}{c}0.13 \\
(1.56)\end{array}$ & $\begin{array}{c}-0.13 \\
(-1.32)\end{array}$ & $\begin{array}{l}-0.44^{\star \star \star} \\
(-3.43)\end{array}$ & $\begin{array}{l}-0.69^{\star * \star} \\
(-3.26)\end{array}$ \\
\hline 4F alpha & $\begin{array}{l}0.21^{\star \star} \\
(1.69)\end{array}$ & $\begin{array}{c}0.04 \\
(0.41)\end{array}$ & $\begin{array}{c}0.09 \\
(1.14)\end{array}$ & $\begin{array}{c}-0.13 \\
(-1.34)\end{array}$ & $\begin{array}{l}-0.40^{\star \star \star} \\
(-2.89)\end{array}$ & $\begin{array}{l}-0.60^{\star * *} \\
(-2.62)\end{array}$ \\
\hline \multicolumn{7}{|l|}{ Panel B. Equal-Weighted Returns } \\
\hline Vol-of-vol & 0.04 & 0.06 & 0.08 & 0.10 & 0.16 & 0.12 \\
\hline Excess return & $\begin{array}{r}0.76^{\star} \\
(1.82)\end{array}$ & $\begin{array}{c}0.70^{\star} \\
(1.70)\end{array}$ & $\begin{array}{c}0.54 \\
(1.33)\end{array}$ & $\begin{array}{c}0.45 \\
(1.07)\end{array}$ & $\begin{array}{c}0.25 \\
(0.60)\end{array}$ & $\begin{array}{l}-0.50^{\star * *} \\
(-3.97)\end{array}$ \\
\hline CAPM alpha & $\begin{array}{c}0.06 \\
(0.45)\end{array}$ & $\begin{array}{c}0.01 \\
(0.08)\end{array}$ & $\begin{array}{c}-0.14 \\
(-1.08)\end{array}$ & $\begin{array}{c}-0.25^{\star} \\
(-1.89)\end{array}$ & $\begin{array}{l}-0.44^{\star \star \star} \\
(-3.14)\end{array}$ & $\begin{array}{l}-0.50^{\star * *} \\
(-3.72)\end{array}$ \\
\hline 3F alpha & $\begin{array}{c}0.00 \\
(-0.01)\end{array}$ & $\begin{array}{c}-0.07 \\
(-0.69)\end{array}$ & $\begin{array}{l}-0.21^{\star *} \\
(-2.20)\end{array}$ & $\begin{array}{l}-0.30^{\star \star \star} \\
(-2.79)\end{array}$ & $\begin{array}{l}-0.51^{\star \star \star} \\
(-4.66)\end{array}$ & $\begin{array}{l}-0.51^{\star \star \star} \\
(-3.97)\end{array}$ \\
\hline 4F alpha & $\begin{array}{c}0.00 \\
(-0.03)\end{array}$ & $\begin{array}{c}-0.03 \\
(-0.32)\end{array}$ & $\begin{array}{l}-0.18^{\star *} \\
(-1.98)\end{array}$ & $\begin{array}{l}-0.25^{\star \star} \\
(-2.41)\end{array}$ & $\begin{array}{l}-0.44^{\star \star \star} \\
(-4.32)\end{array}$ & $\begin{array}{l}-0.44^{\star \star *} \\
(-3.37)\end{array}$ \\
\hline \multicolumn{7}{|l|}{$\underline{\text { Panel C. Portfolio Characteristics }}$} \\
\hline $\begin{array}{l}\text { Avg. no. of stocks/month } \\
\text { Fraction in portfolio next month }\end{array}$ & $\begin{array}{l}234 \\
0.31\end{array}$ & $\begin{array}{ll}234 \\
0.23\end{array}$ & $\begin{array}{l}234 \\
0.22\end{array}$ & $\begin{array}{l}234 \\
0.23\end{array}$ & $\begin{array}{l}234 \\
0.32\end{array}$ & \\
\hline
\end{tabular}

effect of vol-of-vol on future stock returns. The average excess return (4F alpha) difference between the low vol-of-vol and high vol-of-vol portfolio is $-0.50 \%$ $(-0.44 \%)$ per month with a $t$-statistic of $-3.97(-3.37){ }^{7}$ Hence, compared to the value-weighted portfolios, excess returns and alphas are economically smaller (in absolute terms) but still substantial, and with higher statistical significance.

Table 3 suggests that the effect of vol-of-vol on future stock returns tends to be stronger for stocks with higher market capitalization (unlike most other anomalies), thereby causing diminished economic performance with equal weighting. Although the equal-weighted results are of higher statistical significance, we find that larger cap stocks have more option series and more frequently traded option series on them, which contributes to a better quality proxy for expected volatility and, hence, uncertainty about risk. To verify this conjecture, we have examined the predictive power of IV for realized volatility over the

\footnotetext{
${ }^{7}$ The smaller returns, in combination with a relatively high market beta of 1.1-1.2 across all equalweighted portfolios, lead to equal-weighted alphas that are predominantly negative.
} 


\section{FIGURE 1 \\ Vol-of-Vol Effect}

Figure 1 illustrates the monthly performance of portfolios sorted on vol-of-vol. The sample period runs from Jan. 1996 to Oct. 2014. Vol-of-vol is past month's volatility of option-implied volatility (IV) standardized by average IV (see Section II). IV is calculated from at-the-money call and put options with maturity closest to 30 days. Each month we sort stocks in ascending order into quintile portfolios ("Low," "2," "3," "4," and "High") on the basis of vol-of-vol. We use a 1-trading-day implementation lag. In Graph A, we plot the average excess return ("Excess Return"; black bars) and 4-factor alpha ("4F Alpha"; grey bars) of each portfolio, and of the spread between the high vol-of-vol and low vol-of-vol portfolios ("HighLow"), over the subsequent month. In Graph B, we compute the cumulative excess returns ("Excess Return"; dotted lines) and 4-factor alphas ("4-Factor Alpha"; solid lines) of the value-weighed ("VW"; dark gray lines) and equal-weighed ("EW", light gray lines) high-low portfolios (multiplied by -1).
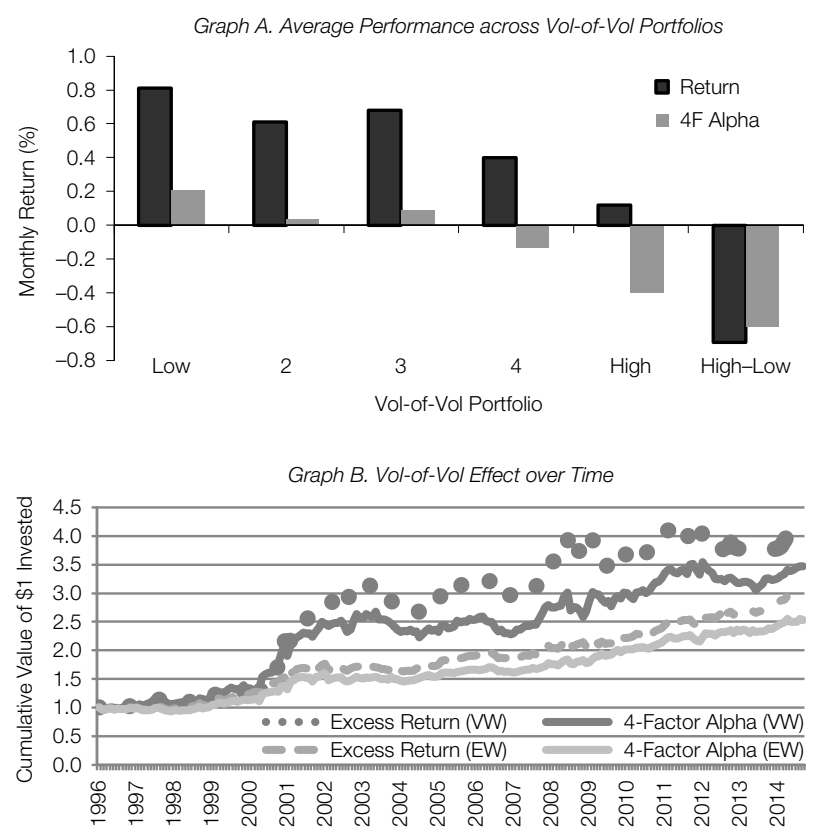

subsequent month for small- and large-cap stocks, and we do indeed find significantly better forecasts for the latter category. For this reason, and because equal-weighted portfolios are tilted toward the smaller stocks that (besides having a lower quality vol-of-vol measure) are economically less important and generally more difficult and costly to trade, we focus on value-weighted returns in the remainder of this article. An argument against our decision to present valueweighted returns is given by Bali and Cakici (2008), who find that equal weights and value weights lead to different results on the link between idiosyncratic volatility and stock returns. Moreover, our sample is already tilted toward the larger caps, as can be seen in Table 1. Therefore, we verify that our findings are robust to equal-weighting the stocks in our sample. For example, for the doublesorting exercise presented below, we also include equal-weighted results in Table A2 of the Internet Appendix.

\section{Number of Stocks in Vol-of-Vol Quintiles}

In Panel $\mathrm{C}$ of Table 3, we compute the average number of stocks in each portfolio (“Avg. no. of stocks/month"). Each portfolio contains on average more 
than 230 stocks. The same holds when studying the number of stocks in each vol-of-vol portfolio over time (unreported). The number of stocks is smallest at the start of our sample in 1996, but the portfolios always contain more than 130 stocks. We also compute the percentage of stocks that stay in the portfolio from one month to the next ("Fraction in portfolio next month"). As shown before, extreme levels of vol-of-vol tend to persist from one month to another: About $30 \%$ of the stocks in the lowest and highest vol-of-vol quintiles stay in their respective quintile, which is more than the $20 \%$ expected under random allocation.

\section{Is the Vol-of-Vol Effect Driven by Other Return Drivers?}

To verify that the vol-of-vol effect is not explained by previously documented anomalies, we control for more than 20 previously documented return drivers using double sorts and Fama-MacBeth (1973) regressions. For the sake of brevity, we present the regressions in Table A1 and the equal-weighted double sorts in Table A2 of the Internet Appendix.

We form quintile portfolios at the end of each month by sorting on the variables that potentially explain the negative vol-of-vol effect. We further sort each quintile portfolio into 5 additional vol-of-vol portfolios, which results in a total of 25 portfolios. Subsequently, we average each of the vol-of-vol portfolios across the 5 quintiles that result from the first sort, producing portfolios with dispersion in vol-of-vol that are similar in terms of the explanatory variables. In addition, we form a high-low vol-of-vol portfolio that buys the resulting high vol-of-vol portfolio and sells the resulting low vol-of-vol portfolio. For each of these portfolios, we compute time-series averages of value-weighted excess returns and alphas over the following month, with Newey-West (1987) adjusted $t$-statistics.

The results are in Table 4. The vol-of-vol effect remains economically and statistically significant after controlling for the canonical stock characteristics in Panel A, and for previously documented risk and other distributional return characteristics to which vol-of-vol is possibly related in Panel B. Because the most liquid stocks tend to be the most relevant from an investor's perspective, we examine the vol-of-vol effect for the largest and most liquid stocks more closely in Panel C. Unlike many other anomalies, the vol-of-vol effect remains pronounced. Panel D demonstrates that the vol-of-vol effect cannot be attributed to a difference in bid-ask noise in option prices, or to previously documented option-related characteristics. Furthermore, in line with our claim that vol-of-vol captures a distinct form of uncertainty, the vol-of-vol effect is not explained by other uncertaintyrelated characteristics presented in Panel E, or by leverage, information delay, and short-sale constraints in Panel $\mathrm{F}^{8}{ }^{2}$ The average excess returns (4F alphas) of the high-low portfolio range from $-0.37 \%(-0.33 \%)$ per month to $-1.11 \%$

\footnotetext{
${ }^{8}$ In double sorts that are not reported in this article (to save space), we find a persistent negative and significant vol-of-vol effect after controlling for co-skewness (Harvey and Siddique (2000)), co-kurtosis (Dittmar (2002)), downside beta (Ang, Chen, and Xing (2006)), and changes in ATM skew (Cremers and Weinbaum (2010)). We further document a persistent, negative, and significant vol-ofvol effect after controlling for various other previously documented cross-sectional return drivers including the return on equity, IBES forecast revisions over the previous month, the Altman distress score, IBES long-term growth expectations, historical sales growth, R\&D/total assets, growth in capital expenditures, PPE to total assets, net payout yield, and change in institutional ownership.
} 
$(-0.94 \%)$ per month with corresponding $t$-statistics of $-2.38(-2.10)$ and -3.12 (-2.64). Hence, although Table 2 suggests that many of these stock characteristics vary significantly across vol-of-vol portfolios, the results in Table 4 imply that the predictive ability of vol-of-vol is distinct from these previously documented cross-sectional predictors. Furthermore, the Fama-MacBeth (1973) regressions in the Internet Appendix indicate that the negative relation between vol-of-vol as a characteristic and future returns is robust to simultaneously controlling for the subsets of variables in Table 4. The coefficient on vol-of-vol remains highly significant with $t$-statistics generally well above 3 , indicating that the vol-of-vol effect is not simply a combination of the cross-sectional return predictors given earlier.

\title{
D. Subsample Analysis and Robustness
}

The negative vol-of-vol effect might be concentrated in a particular subperiod. In Graph B of Figure 1 we depict the cumulative excess returns and 4-factor alphas on the value-weighted and equal-weighted high-low vol-of-vol portfolio over our sample period, multiplied by -1 . Excess returns and 4-factor alphas

\section{TABLE 4}

Value-Weighted Returns of Portfolios

Sorted by Stock Characteristics and Vol-of-Vol

\begin{abstract}
Table 4 reports average monthly value-weighted returns of portfolios sorted by stock characteristics and vol-of-vol over our sample period from Jan. 1996 to Oct. 2014. Vol-of-vol is past month's volatility of option-implied volatility (IV), standardized by average IV (see Section II). IV is calculated from at-the-money call and put options with maturity closest to 30 days. Each month we sort stocks in ascending order into quintile portfolios on the basis of one of the characteristics described in Section III.A and defined in the Appendix. Within each characteristic quintile, we sort stocks into 5 additional portfolios ("Low," "2," "3," "4," and "High") based on vol-of-vol and then average each of the vol-of-vol portfolios across the 5 quintiles that result from the first sort. We compute the returns on the resulting portfolios over the subsequent month, as well as the difference between the high portfolio and the low portfolio ("High-Low"). We use a 1-trading-day implementation lag and value weigh stocks in each portfolio. The column labeled "High-Low (4F Alpha)" presents the difference in 4-factor alphas between the high portfolio and the low portfolio. For liquidity characteristics, this table presents returns of the most liquid portfolios. For the remaining characteristics, it presents the return of each vol-of-vol quintile, averaged over the 5 characteristic-sorted portfolios. We report the Newey-West (1987) corrected $t$-statistics in parentheses. ${ }^{*},{ }^{* *}$, and ${ }^{* * *}$ indicate significance at the $10 \%, 5 \%$, and $1 \%$ levels, respectively.
\end{abstract}

\begin{tabular}{|c|c|c|c|c|c|c|c|}
\hline Statistics & Low & 2 & 3 & 4 & High & High-Low & $\begin{array}{l}\text { High-Low } \\
\text { (4F Alpha) }\end{array}$ \\
\hline \multicolumn{8}{|c|}{ Panel A. Canonical Characteristics } \\
\hline BETA & $\begin{array}{l}0.69^{\star *} \\
(1.98)\end{array}$ & $\begin{array}{r}0.58^{\star} \\
(1.72)\end{array}$ & $\begin{array}{c}0.68^{*} \\
(1.94)\end{array}$ & $\begin{array}{c}0.39 \\
(1.10)\end{array}$ & $\begin{array}{c}0.29 \\
(0.70)\end{array}$ & $\begin{array}{l}-0.40^{\star \star} \\
(-2.46)\end{array}$ & $\begin{array}{l}-0.39^{\star \star} \\
(-2.24)\end{array}$ \\
\hline BOOK_TO_MARKET & $\begin{array}{l}0.81^{\star \star} \\
(2.46)\end{array}$ & $\begin{array}{l}0.76^{\star \star} \\
(2.42)\end{array}$ & $\begin{array}{r}0.65^{\star} \\
(1.93)\end{array}$ & $\begin{array}{c}0.51 \\
(1.54)\end{array}$ & $\begin{array}{c}0.24 \\
(0.68)\end{array}$ & $\begin{array}{l}-0.56^{\star \star \star} \\
(-3.18)\end{array}$ & $\begin{array}{l}-0.51^{\star \star \star} \\
(-2.87)\end{array}$ \\
\hline SIZE & $\begin{array}{c}0.69 \\
(1.60)\end{array}$ & $\begin{array}{c}0.71^{*} \\
(1.66)\end{array}$ & $\begin{array}{c}0.51 \\
(1.20)\end{array}$ & $\begin{array}{c}0.50 \\
(1.13)\end{array}$ & $\begin{array}{c}0.26 \\
(0.61)\end{array}$ & $\begin{array}{l}-0.43^{\star \star \star} \\
(-3.05)\end{array}$ & $\begin{array}{l}-0.36^{\star \star} \\
(-2.55)\end{array}$ \\
\hline MOMENTUM & $\begin{array}{l}0.86^{\star \star \star} \\
(2.58)\end{array}$ & $\begin{array}{l}0.70^{\star \star} \\
(2.14)\end{array}$ & $\begin{array}{l}0.76^{\star \star} \\
(2.17)\end{array}$ & $\begin{array}{c}0.51 \\
(1.37)\end{array}$ & $\begin{array}{c}0.17 \\
(0.43)\end{array}$ & $\begin{array}{l}-0.70^{\star \star \star} \\
(-3.72)\end{array}$ & $\begin{array}{l}-0.66^{\star \star \star} \\
(-3.48)\end{array}$ \\
\hline SHORT_TERM_REVERSAL & $\begin{array}{l}0.78^{\star \star} \\
(2.39)\end{array}$ & $\begin{array}{l}0.68^{\star \star} \\
(2.04)\end{array}$ & $\begin{array}{c}0.63^{\star} \\
(1.80)\end{array}$ & $\begin{array}{c}0.37 \\
(0.98)\end{array}$ & $\begin{array}{c}0.15 \\
(0.40)\end{array}$ & $\begin{array}{l}-0.62^{\star \star \star} \\
(-3.25)\end{array}$ & $\begin{array}{l}-0.58^{\star \star \star} \\
(-2.96)\end{array}$ \\
\hline \multicolumn{8}{|c|}{ Panel B. Returns Distribution Characteristics } \\
\hline IDIOSYNC_VOLATILITY & $\begin{array}{c}0.72^{\star} \\
(1.73)\end{array}$ & $\begin{array}{c}0.65 \\
(1.45)\end{array}$ & $\begin{array}{c}0.62 \\
(1.39)\end{array}$ & $\begin{array}{c}0.34 \\
(0.70)\end{array}$ & $\begin{array}{c}-0.11 \\
(-0.23)\end{array}$ & $\begin{array}{l}-0.84^{\star \star \star} \\
(-3.81)\end{array}$ & $\begin{array}{l}-0.77^{\star \star \star} \\
(-3.57)\end{array}$ \\
\hline MAXIMUM_RETURN & $\begin{array}{l}0.77^{\star \star} \\
(2.01)\end{array}$ & $\begin{array}{c}0.61^{*} \\
(1.67)\end{array}$ & $\begin{array}{c}0.52 \\
(1.37)\end{array}$ & $\begin{array}{c}0.43 \\
(1.09)\end{array}$ & $\begin{array}{c}0.09 \\
(0.23)\end{array}$ & $\begin{array}{l}-0.68^{\star \star \star} \\
(-3.70)\end{array}$ & $\begin{array}{l}-0.62^{\star \star \star} \\
(-3.22)\end{array}$ \\
\hline SKEWNESS & $\begin{array}{l}0.69^{\star \star} \\
(2.09)\end{array}$ & $\begin{array}{l}0.70^{\star \star} \\
(2.24)\end{array}$ & $\begin{array}{c}0.64^{\star} \\
(1.87)\end{array}$ & $\begin{array}{c}0.43 \\
(1.22)\end{array}$ & $\begin{array}{c}0.09 \\
(0.22)\end{array}$ & $\begin{array}{l}-0.60^{\star \star \star} \\
(-2.77)\end{array}$ & $\begin{array}{l}-0.51^{\star \star} \\
(-2.38)\end{array}$ \\
\hline KURTOSIS & $\begin{array}{l}0.80^{\star \star} \\
(2.52)\end{array}$ & $\begin{array}{l}0.69^{\star *} \\
(2.17)\end{array}$ & $\begin{array}{r}0.62^{*} \\
(1.90)\end{array}$ & $\begin{array}{c}0.45 \\
(1.27)\end{array}$ & $\begin{array}{c}0.22 \\
(0.55)\end{array}$ & $\begin{array}{l}-0.58^{\star \star \star} \\
(-2.73)\end{array}$ & $\begin{array}{l}-0.53^{\star \star} \\
(-2.36)\end{array}$ \\
\hline
\end{tabular}


TABLE 4 (continued)

Value-Weighted Returns of Portfolios

Sorted by Stock Characteristics and Vol-of-Vol

\begin{tabular}{|c|c|c|c|c|c|c|c|}
\hline Statistics & Low & 2 & 3 & 4 & High & High-Low & $\begin{array}{l}\text { High-Low } \\
\text { (4F Alpha) }\end{array}$ \\
\hline \multicolumn{8}{|c|}{ Panel C. Liquidity Characteristics (Largest and Most Liquid Stocks) } \\
\hline $\begin{array}{l}\text { Largest stocks } \\
\text { (top size quintile) }\end{array}$ & $\begin{array}{l}0.72^{\star \star} \\
(2.39)\end{array}$ & $\begin{array}{l}0.82^{\star \star} \\
(2.52)\end{array}$ & $\begin{array}{l}0.79^{* *} \\
(2.37)\end{array}$ & $\begin{array}{c}0.52 \\
(1.46)\end{array}$ & $\begin{array}{l}0.21 \\
(0.54)\end{array}$ & $\begin{array}{l}-0.51^{\star \star} \\
(-2.35)\end{array}$ & $\begin{array}{l}-0.50^{\star \star} \\
(-2.45)\end{array}$ \\
\hline $\begin{array}{l}\text { Largest stocks } \\
\text { (NYSE stocks only) }\end{array}$ & $\begin{array}{l}0.75^{\star \star} \\
(2.50)\end{array}$ & $\begin{array}{l}0.66^{\star \star} \\
(2.26)\end{array}$ & $\begin{array}{l}0.66^{* *} \\
(2.24)\end{array}$ & $\begin{array}{c}0.44 \\
(1.38)\end{array}$ & $\begin{array}{l}0.1 \\
(0.28)\end{array}$ & $\begin{array}{l}-0.65^{\star \star \star} \\
(-2.90)\end{array}$ & $\begin{array}{l}-0.54^{\star \star} \\
(-2.41)\end{array}$ \\
\hline $\begin{array}{l}\text { Most liquid stocks } \\
\text { (AMIHUD_ILLIQUIDITY) }\end{array}$ & $\begin{array}{l}0.77^{\star \star} \\
(2.63)\end{array}$ & $\begin{array}{l}0.72^{\star \star} \\
(2.42)\end{array}$ & $\begin{array}{l}0.67^{* *} \\
(2.15)\end{array}$ & $\begin{array}{c}0.44 \\
(1.26)\end{array}$ & $\begin{array}{c}0.20 \\
(0.50)\end{array}$ & $\begin{array}{l}-0.57^{\star \star} \\
(-2.28)\end{array}$ & $\begin{array}{l}-0.51^{\star \star} \\
(-2.16)\end{array}$ \\
\hline $\begin{array}{l}\text { Most liquid stocks } \\
\text { (turnover) }\end{array}$ & $\begin{array}{c}0.79 \\
(1.49)\end{array}$ & $\begin{array}{r}1.04^{*} \\
(1.89)\end{array}$ & $\begin{array}{c}0.67 \\
(1.19)\end{array}$ & $\begin{array}{l}0.21 \\
(0.36)\end{array}$ & $\begin{array}{l}-0.33 \\
(-0.55)\end{array}$ & $\begin{array}{l}-1.11^{\star \star \star} \\
(-3.12)\end{array}$ & $\begin{array}{l}-0.94^{\star \star \star} \\
(-2.64)\end{array}$ \\
\hline \multicolumn{8}{|c|}{ Panel D. Option-Based Characteristics } \\
\hline OPTION_BID_ASK_SPREAD & $\begin{array}{l}0.75^{\star \star} \\
(2.33)\end{array}$ & $\begin{array}{l}0.78^{\star \star} \\
(2.39)\end{array}$ & $\begin{array}{l}0.69^{* *} \\
(2.04)\end{array}$ & $\begin{array}{c}0.50 \\
(1.43)\end{array}$ & $\begin{array}{c}0.23 \\
(0.62)\end{array}$ & $\begin{array}{l}-0.52^{\star \star \star} \\
(-2.73)\end{array}$ & $\begin{array}{l}-0.44^{\star \star} \\
(-2.41)\end{array}$ \\
\hline ATM_SKEW & $\begin{array}{l}0.76^{\star \star} \\
(2.35)\end{array}$ & $\begin{array}{l}0.70^{\star *} \\
(2.15)\end{array}$ & $\begin{array}{l}0.69^{* *} \\
(1.98)\end{array}$ & $\begin{array}{c}0.53 \\
(1.46)\end{array}$ & $\begin{array}{l}0.06 \\
(0.14)\end{array}$ & $\begin{array}{l}-0.70^{\star \star \star} \\
(-2.96)\end{array}$ & $\begin{array}{l}-0.65^{\star \star \star} \\
(-2.90)\end{array}$ \\
\hline OTM_SKEW & $\begin{array}{l}0.75^{\star \star} \\
(2.31)\end{array}$ & $\begin{array}{l}0.69^{\star *} \\
(2.12)\end{array}$ & $\begin{array}{l}0.67^{* *} \\
(2.04)\end{array}$ & $\begin{array}{c}0.51 \\
(1.41)\end{array}$ & $\begin{array}{l}0.08 \\
(0.20)\end{array}$ & $\begin{array}{l}-0.67^{\star \star \star} \\
(-2.93)\end{array}$ & $\begin{array}{l}-0.60^{\star \star \star} \\
(-2.67)\end{array}$ \\
\hline IV_RV_SPREAD & $\begin{array}{l}0.76^{\star \star} \\
(2.25)\end{array}$ & $\begin{array}{r}0.62^{*} \\
(1.85)\end{array}$ & $\begin{array}{r}0.60^{*} \\
(1.72)\end{array}$ & $\begin{array}{c}0.44 \\
(1.20)\end{array}$ & $\begin{array}{c}0.16 \\
(0.41)\end{array}$ & $\begin{array}{l}-0.60^{\star \star \star} \\
(-2.98)\end{array}$ & $\begin{array}{l}-0.55^{\star \star} \\
(-2.56)\end{array}$ \\
\hline$\triangle \mathrm{CALL} / \mathrm{IV}$ & $\begin{array}{l}0.82^{\star \star} \\
(2.31)\end{array}$ & $\begin{array}{l}0.85^{\star *} \\
(2.45)\end{array}$ & $\begin{array}{c}0.56^{*} \\
(1.63)\end{array}$ & $\begin{array}{c}0.43 \\
(1.32)\end{array}$ & $\begin{array}{c}0.31 \\
(0.86)\end{array}$ & $\begin{array}{l}-0.51^{\star *} \\
(-2.51)\end{array}$ & $\begin{array}{l}-0.44^{\star \star} \\
(-2.14)\end{array}$ \\
\hline$\triangle P U T \_I V$ & $\begin{array}{l}0.77^{\star \star} \\
(2.15)\end{array}$ & $\begin{array}{l}0.83^{\star \star} \\
(2.39)\end{array}$ & $\begin{array}{c}0.62^{*} \\
(1.78)\end{array}$ & $\begin{array}{c}0.45 \\
(1.32)\end{array}$ & $\begin{array}{c}0.25 \\
(0.70)\end{array}$ & $\begin{array}{l}-0.52^{\star \star \star} \\
(-2.68)\end{array}$ & $\begin{array}{l}-0.45^{\star \star} \\
(-2.23)\end{array}$ \\
\hline \multicolumn{8}{|c|}{ Panel E. Uncertainty-Related Characteristics } \\
\hline AGE & $\begin{array}{l}0.75^{\star \star} \\
(2.17)\end{array}$ & $\begin{array}{c}0.65^{\star} \\
(1.66)\end{array}$ & $\begin{array}{c}0.69^{*} \\
(1.78)\end{array}$ & $\begin{array}{c}0.37 \\
(0.89)\end{array}$ & $\begin{array}{c}0.08 \\
(0.18)\end{array}$ & $\begin{array}{l}-0.68^{\star \star \star} \\
(-3.24)\end{array}$ & $\begin{array}{l}-0.56^{\star \star \star} \\
(-3.00)\end{array}$ \\
\hline ANALYST_COVERAGE & $\begin{array}{r}0.72^{*} \\
(1.82)\end{array}$ & $\begin{array}{c}0.59 \\
(1.45)\end{array}$ & $\begin{array}{c}0.52 \\
(1.19)\end{array}$ & $\begin{array}{c}0.18 \\
(0.43)\end{array}$ & $\begin{array}{c}-0.05 \\
(-0.11)\end{array}$ & $\begin{array}{l}-0.76^{\star \star \star} \\
(-3.96)\end{array}$ & $\begin{array}{l}-0.68^{\star \star \star} \\
(-3.37)\end{array}$ \\
\hline FORECAST_DISPERSION & $\begin{array}{l}0.79^{\star \star} \\
(2.31)\end{array}$ & $\begin{array}{l}0.79^{\star \star} \\
(2.41)\end{array}$ & $\begin{array}{c}0.58 \\
(1.62)\end{array}$ & $\begin{array}{c}0.39 \\
(1.05)\end{array}$ & $\begin{array}{c}0.15 \\
(0.38)\end{array}$ & $\begin{array}{l}-0.64^{\star \star \star} \\
(-3.01)\end{array}$ & $\begin{array}{l}-0.50^{\star \star \star} \\
(-2.57)\end{array}$ \\
\hline VOLATILITY & $\begin{array}{r}0.78^{\star} \\
(1.87)\end{array}$ & $\begin{array}{c}0.72^{\star} \\
(1.70)\end{array}$ & $\begin{array}{c}0.56 \\
(1.33)\end{array}$ & $\begin{array}{c}0.38 \\
(0.86)\end{array}$ & $\begin{array}{l}0.1 \\
(0.23)\end{array}$ & $\begin{array}{l}-0.68^{\star \star \star} \\
(-3.52)\end{array}$ & $\begin{array}{l}-0.59^{\star \star \star} \\
(-2.87)\end{array}$ \\
\hline PRIVATE_INFORMATION & $\begin{array}{l}0.72^{\star \star} \\
(2.37)\end{array}$ & $\begin{array}{l}0.62^{\star \star} \\
(2.02)\end{array}$ & $\begin{array}{c}0.63 \\
(2.03)\end{array}$ & $\begin{array}{c}0.34 \\
(1.02)\end{array}$ & $\begin{array}{c}0.34 \\
(1.00)\end{array}$ & $\begin{array}{l}-0.38^{\star \star} \\
(-2.50)\end{array}$ & $\begin{array}{l}-0.33^{\star \star} \\
(-2.10)\end{array}$ \\
\hline \multicolumn{8}{|l|}{ Panel F. Other Characteristics } \\
\hline LEVERAGE & $\begin{array}{l}0.72^{\star \star} \\
(2.17)\end{array}$ & $\begin{array}{c}0.8^{\star \star} \\
(2.40)\end{array}$ & $\begin{array}{r}0.65^{*} \\
(1.88)\end{array}$ & $\begin{array}{c}0.50 \\
(1.37)\end{array}$ & $\begin{array}{c}0.23 \\
(0.63)\end{array}$ & $\begin{array}{l}-0.48^{\star \star \star} \\
(-2.72)\end{array}$ & $\begin{array}{l}-0.37^{\star \star} \\
(-2.16)\end{array}$ \\
\hline STOCK_PRICE_DELAY & $\begin{array}{l}0.75^{\star \star} \\
(2.50)\end{array}$ & $\begin{array}{l}0.61^{\star \star} \\
(2.11)\end{array}$ & $\begin{array}{l}0.68^{* *} \\
(2.33)\end{array}$ & $\begin{array}{c}0.49 \\
(1.63)\end{array}$ & $\begin{array}{c}0.39 \\
(1.18)\end{array}$ & $\begin{array}{l}-0.37^{\star \star} \\
(-2.38)\end{array}$ & $\begin{array}{l}-0.35^{\star \star} \\
(-2.08)\end{array}$ \\
\hline SHORT_SALE_CONSTRAINTS & $\begin{array}{l}0.81^{\text {}}(2.59) \\
(2.59\end{array}$ & $\begin{array}{c}0.70^{\star *} \\
(2.11)\end{array}$ & $\begin{array}{l}0.73^{* *} \\
(2.10)\end{array}$ & $\begin{array}{c}0.41 \\
(1.12)\end{array}$ & $\begin{array}{c}0.16 \\
(0.40)\end{array}$ & $\begin{array}{l}-0.65^{\star \star \star} \\
(-3.07)\end{array}$ & $\begin{array}{l}-0.61^{\star \star \star} \\
(-2.93)\end{array}$ \\
\hline
\end{tabular}

are economically large throughout the sample period, seem not concentrated in a particular period, but are stronger in the first subperiod for value-weighted portfolios. Closer inspection reveals that the negative vol-of-vol effect is present in more than $60 \%$ of the months, and negative returns tend to be larger (in absolute terms) than positive returns for most years throughout the sample period.

Next, we examine average (rather than cumulative) excess returns and $4 \mathrm{~F}$ alphas after splitting the sample in 2 parts. In the top rows of Table 5, valueweighted excess returns (4F alphas) are $-1.07(-0.78)$ and $-0.34(-0.35)$ for the 1996-2004 and 2005-2014 subsamples, respectively. Corresponding $t$-values are $-2.57(-1.85)$ and $-1.54(-1.57)$. These $t$-values do not always scrape 
past the conventional $5 \%$ or $10 \%$ threshold (significance is at the $12 \%$ level or better), but we should be careful for Type II error (false negatives) when testing for the vol-of-vol effect in relatively short subsample periods. In fact, the $t$-values in the second subperiod (loosely) translate into high and economically meaningful Sharpe ratios of $1.54 / \sqrt{9}=0.51$ and $1.57 / \sqrt{9}=0.52$ per year. Furthermore, the second set of rows shows that equal-weighted excess returns and $4 \mathrm{~F}$ alphas are highly significant in both the 1996-2004 and 2005-2014 periods (i.e., -0.47 and -0.45 with $t$-values of -3.45 and -3.38 , respectively). This leaves us to conclude that the vol-of-vol effect is present in both periods. ${ }^{9}$

In the remainder of Table 5, we further examine the predictive power of volof-vol by splitting our 1996-2014 sample period based on economic conditions. We distinguish recession versus no-recession subsamples as indicated by the

\section{TABLE 5}

\section{Subsample Analysis}

\begin{tabular}{|c|c|c|c|c|c|}
\hline Subsample & No. of Obs. & Low & High & High-Low & $\begin{array}{l}\text { High-Low } \\
\text { (4F Alpha) }\end{array}$ \\
\hline 1996-2004 VW & 107 & $\begin{array}{l}0.88^{* *} \\
(2.02)\end{array}$ & $\begin{array}{c}-0.19 \\
(-0.30)\end{array}$ & $\begin{array}{l}-1.07^{\text {}} \\
(-2.57)\end{array}$ & $\begin{array}{r}-0.78^{*} \\
(-1.85)\end{array}$ \\
\hline 2005-2014 VW & 117 & $\begin{array}{r}0.75^{*} \\
(1.68)\end{array}$ & $\begin{array}{c}0.41 \\
(0.87)\end{array}$ & $\begin{array}{c}-0.34 \\
(-1.54)\end{array}$ & $\begin{array}{c}-0.35 \\
(-1.57)\end{array}$ \\
\hline 1996-2004 EW & 107 & $\begin{array}{c}0.57 \\
(0.89)\end{array}$ & $\begin{array}{c}0.03 \\
(0.04)\end{array}$ & $\begin{array}{l}-0.54^{\star \star} \\
(-2.45)\end{array}$ & $\begin{array}{l}-0.47^{\text {} \star \star \star ~} \\
(-3.45)\end{array}$ \\
\hline 2005-2014 EW & 117 & $\begin{array}{l}-0.31 \\
(-163)\end{array}$ & $\begin{array}{l}-0.69^{\star \star \star} \\
(-3.82)\end{array}$ & $\begin{array}{l}-0.38 \\
(-1.48)\end{array}$ & $\begin{array}{l}-0.45^{\star \star \star} \\
(-3.38)\end{array}$ \\
\hline Recession & 26 & $\begin{array}{c}-1.41 \\
(-0.97)\end{array}$ & $\begin{array}{c}-1.71 \\
(-1.04)\end{array}$ & $\begin{array}{l}-0.30 \\
(-0.46)\end{array}$ & $\begin{array}{c}-0.33 \\
(-0.56)\end{array}$ \\
\hline No recession & 198 & $\begin{array}{l}1.10^{\star \star *} \\
(3.90)\end{array}$ & $\begin{array}{c}0.37 \\
(0.96)\end{array}$ & $\begin{array}{l}-0.74^{\star \star \star} \\
(-2.95)\end{array}$ & $\begin{array}{l}-0.57^{\star \star} \\
(-2.25)\end{array}$ \\
\hline CFNAI $<0$ & 110 & $\begin{array}{l}1.32^{\star \star *} \\
(3.61)\end{array}$ & $\begin{array}{c}0.92^{\star \star} \\
(2.20)\end{array}$ & $\begin{array}{c}-0.39^{\star} \\
(-1.76)\end{array}$ & $\begin{array}{l}-0.97^{\star \star} \\
(-2.48)\end{array}$ \\
\hline $\mathrm{CFNAI} \geq 0$ & 114 & $\begin{array}{c}0.13 \\
(0.95)\end{array}$ & $\begin{array}{c}-0.20 \\
(-1.64)\end{array}$ & $\begin{array}{c}-0.33 \\
(-1.59)\end{array}$ & $\begin{array}{l}-0.87^{\star \star} \\
(-2.37)\end{array}$ \\
\hline S\&P 500 return $<0$ & 85 & $\begin{array}{c}0.57 \\
(0.92)\end{array}$ & $\begin{array}{c}-0.26 \\
(-0.36)\end{array}$ & $\begin{array}{r}-0.83^{*} \\
(-1.76)\end{array}$ & $\begin{array}{l}-1.05^{\star} \\
(-1.92)\end{array}$ \\
\hline S\&P 500 return $\geq 0$ & 139 & $\begin{array}{l}0.96^{* * *} \\
(3.05)\end{array}$ & $\begin{array}{c}0.36 \\
(0.83)\end{array}$ & $\begin{array}{l}-0.60^{\star \star} \\
(-2.33)\end{array}$ & $\begin{array}{l}-0.53^{\star \star} \\
(-2.25)\end{array}$ \\
\hline
\end{tabular}

\footnotetext{
${ }^{9}$ Although splitting the sample into 3 subperiods (1996-2001, 2002-2007, and 2008-2014) further decreases sample size and statistical power, average value-weighted excess returns (4F alphas) are again always negative and evolve from $-1.6 \%(-1.2 \%)$ to $-0.4 \%(-0.4 \%)$ to $-0.2 \%(-0.2 \%)$. Equal-weighted excess returns (4F alphas) go from $-0.8 \%(-0.2 \%)$ to $-0.6 \%(-0.4 \%)$ to $-0.3 \%$ $(-0.5 \%)$. Furthermore, we calculate sup $F$-test statistics (Andrews (1993), Bai and Perron (1998)) that test for 1 or more endogenously determined structural breaks but do not find clear evidence of such breaks. Finally, running regressions of monthly vol-of-vol returns on a time trend yields a significant negative average vol-of-vol effect, but insignificant coefficients on the time trend variable. Year dummies are also jointly insignificant when included.
} 
National Bureau of Economic Research (NBER) Business Cycle Dating Committee, subsamples based on changes in economic activity as measured by a positive or negative 3-month moving average of the Chicago Fed National Activity Index (CFNAI), and up-market versus down-market subsamples using an indicator based on whether the Standard \& Poor's (S\&P) 500 index experienced a positive or a negative return over the month preceding portfolio formation. Although limited subsample size again decreases statistical power, we find that most excess returns or 4-factor alphas are negative and significant, except for the recessions subsample that has only 26 observations. Hence, although our sample period contains extensive periods dominated by either positive news (e.g., the Internet bubble run-up) or negative news (e.g., the 2007-2008 crisis), the vol-of-vol effect does not seem to be driven by a specific period.

Finally, the Internet Appendix presents additional results that demonstrate the robustness of our findings. Figure A1 shows that the vol-of-vol effect continues to accumulate returns at a slowly decreasing rate for up to 24 months after portfolio formation, indicating a long-term price adjustment rather than a temporary effect. In Table A3, we observe that the vol-of-vol effect is not significantly driven by industry clustering within the portfolios, and is also present after first sorting on IV before sorting on vol-of-vol. Furthermore, the results are insensitive to defining vol-of-vol without scaling by the average IV; accounting for persistence and asymmetric jump behavior of volatility by calculating vol-of-vol using the volatility of log-transformed IV, the volatility of IV increments (which implicitly assumes a random walk), or the volatility of log-transformed IV increments; or after purging the impact of a volatility risk premium by estimating expected volatility based on the fitted values of a regression of 1-month-ahead realized volatility on the current values of IV and realized volatility, in the spirit of Drechsler and Yaron (2011). The effect of vol-of-vol on future stock returns is negative but insignificant when we use 3, 6, and 12 months of IVs to compute vol-of-vol. ${ }^{10}$ This indicates that the effect is mainly present when the most recent variation in IV is used to measure uncertainty about risk. We attribute this to vol-of-vol computed over the most recent month being a better reflection of ex ante uncertainty about risk than vol-of-vol computed using a longer historical window. ${ }^{11}$

\section{E. European Evidence}

Regardless of the preceding analyses, the vol-of-vol effect may be specific to the post-1996 U.S. market. To alleviate this concern, we test the cross-sectional relation between vol-of-vol and subsequent stock returns for a sample of European stocks using European OptionMetrics data. Total monthly returns for all

\footnotetext{
${ }^{10}$ We note, however, that when we impose a longer holding period, the significance of computing vol-of-vol computed over longer historical windows tends to increase.

${ }^{11}$ In line with this conjecture, (unreported) results show that vol-of-vol measured over the same month as returns (i.e., contemporaneously) strongly explains returns, and when contemporaneous volof-vol is regressed against vol-of-vol measured over the past 1, 3, 6, or 12 months, the fit of these regressions gradually improves when more recent data are used. These results suggest that vol-of-vol computed over an even shorter horizon might further improve estimating ex ante uncertainty. In our current data set, vol-of-vol would then be calculated from only a very few IV observations, but future research may exploit intraday quotes on IV to compute a better measure of ex ante vol-of-vol. At this point, we are not aware of such data that are of high quality and have sufficient history.
} 
remaining stocks are obtained from Factset/Interactive Data EXSHARE. The 1-, 3-, and 4-factor alphas are calculated using the European factors from Kenneth French's Web site.

The European OptionMetrics IvyDB Europe database starts in Jan. 2002 and runs to May 2012. The data contain options from Austria, Belgium, Finland, France, Germany, Italy, the Netherlands, Norway, Spain, Sweden, Switzerland, and the United Kingdom. We follow the methodology outlined in Section III for U.S. options wherever possible but make adjustments to account for the specifics of European option markets. Differences in methodology relate primarily to the choice of maturity (which we allow to vary across countries, based on option coverage) and sorting procedure (we compare stocks only with those from the same country). Section $C$ of the Internet Appendix describes our sample choices and the adjustments in detail. After calculating the vol-of-vol measure, we sort stocks into quintiles before calculating both equal- and value-weighted excess returns and alphas.

This results in quintile portfolios that each contains 40-50 stocks per month; European stock option markets are smaller than their U.S. counterpart. The results presented in Table 6 indicate that the vol-of-vol effect also exists in Europe. Although the portfolios do not vary monotonically, the high-low portfolio

\section{TABLE 6}

Returns on Portfolios Sorted by Vol-of-Vol: European Data

\begin{tabular}{|c|c|c|c|c|c|c|}
\hline & Low & 2 & 3 & 4 & Mign & \\
\hline \multicolumn{7}{|c|}{ Panel A. Value-Weighted Returns } \\
\hline Excess return & $\begin{array}{c}0.89 \\
(1.37)\end{array}$ & $\begin{array}{c}0.42 \\
(0.70)\end{array}$ & $\begin{array}{c}0.43 \\
(0.68)\end{array}$ & $\begin{array}{c}0.10 \\
(0.16)\end{array}$ & $\begin{array}{c}0.40 \\
(0.64)\end{array}$ & $\begin{array}{l}-0.48^{\star \star} \\
(-2.00)\end{array}$ \\
\hline CAPM alpha & $\begin{array}{c}0.34 \\
(1.81)\end{array}$ & $\begin{array}{c}-0.11 \\
(-0.80)\end{array}$ & $\begin{array}{c}-0.12 \\
(-0.85)\end{array}$ & $\begin{array}{c}-0.45 \\
(-3.02)\end{array}$ & $\begin{array}{c}-0.16 \\
(-0.95)\end{array}$ & $\begin{array}{l}-0.50^{\star \star} \\
(-2.03)\end{array}$ \\
\hline 3F alpha & $\begin{array}{c}0.44 \\
(2.11)\end{array}$ & $\begin{array}{c}-0.04 \\
(-0.33)\end{array}$ & $\begin{array}{c}-0.03 \\
(-0.25)\end{array}$ & $\begin{array}{c}-0.35 \\
(-2.58)\end{array}$ & $\begin{array}{l}-0.08 \\
(-0.54)\end{array}$ & $\begin{array}{l}-0.53^{\star *} \\
(-2.05)\end{array}$ \\
\hline 4F alpha & $\begin{array}{c}0.56 \\
(2.57)\end{array}$ & $\begin{array}{l}-0.07 \\
(-0.47)\end{array}$ & $\begin{array}{l}-0.01 \\
(-0.05)\end{array}$ & $\begin{array}{c}-0.21 \\
(-1.51)\end{array}$ & $\begin{array}{c}0.05 \\
(0.30)\end{array}$ & $\begin{array}{l}-0.51^{* *} \\
(-1.98)\end{array}$ \\
\hline \multicolumn{7}{|c|}{ Panel B. Equal-Weighted Returns } \\
\hline Excess return & $\begin{array}{c}0.83 \\
(1.13)\end{array}$ & $\begin{array}{c}0.53 \\
(0.74)\end{array}$ & $\begin{array}{c}0.56 \\
(0.79)\end{array}$ & $\begin{array}{c}0.46 \\
(0.61)\end{array}$ & $\begin{array}{c}0.49 \\
(0.66)\end{array}$ & $\begin{array}{c}-0.34^{\star} \\
(-1.84)\end{array}$ \\
\hline CAPM alpha & $\begin{array}{c}0.20 \\
(1.11)\end{array}$ & $\begin{array}{c}-0.09 \\
(-0.56)\end{array}$ & $\begin{array}{c}-0.06 \\
(-0.37)\end{array}$ & $\begin{array}{c}-0.19 \\
(-1.03)\end{array}$ & $\begin{array}{l}-0.15 \\
(-0.87)\end{array}$ & $\begin{array}{l}-0.36^{*} \\
(-1.95)\end{array}$ \\
\hline 3F alpha & $\begin{array}{c}0.23 \\
(1.22)\end{array}$ & $\begin{array}{l}-0.07 \\
(-0.4)\end{array}$ & $\begin{array}{c}0.00 \\
(0.01)\end{array}$ & $\begin{array}{c}-0.14 \\
(-0.79)\end{array}$ & $\begin{array}{l}-0.15 \\
(-0.88)\end{array}$ & $\begin{array}{l}-0.38^{\star *} \\
(-2.13)\end{array}$ \\
\hline $4 \mathrm{~F}$ alpha & $\begin{array}{l}0.52^{\star \star *} \\
(2.97)\end{array}$ & $\begin{array}{c}0.10 \\
(0.58)\end{array}$ & $\begin{array}{c}0.18 \\
(1.04)\end{array}$ & $\begin{array}{c}0.20 \\
(1.23)\end{array}$ & $\begin{array}{c}0.18 \\
(1.13)\end{array}$ & $\begin{array}{r}-0.34^{*} \\
(-1.93)\end{array}$ \\
\hline
\end{tabular}


exhibits significant negative excess returns and 1-, 3-, and 4-factor alphas for both value-weighted and equal-weighted portfolios of $-0.34 \%$ per month, or about $4 \%$ a year. Interestingly, in Europe the vol-of-vol effect seems to be driven mainly by the long side. In conclusion, the vol-of-vol effect is not only found in the U.S. but is also present in European stock markets.

\section{Is Vol-of-Vol a Priced Risk Factor?}

The vol-of-vol effect may arise because exposures to an aggregate vol-of-vol factor, rather than to individual stock vol-of-vol factors, are priced. For example, exposures to vol-of-vol might be priced in a factor model as in Ross's (1976) arbitrage pricing theory, or if vol-of-vol provides a hedge against deteriorating investment opportunities (Campbell (1993), (1996), Ang, Hodrick, et al. (2006)).

To empirically test for factor pricing of vol-of-vol, we construct a vol-ofvol factor either from returns on the value-weighted high-low vol-of-vol quintile portfolio, or by computing vol-of-vol directly from market-level IV (i.e., from ATM S\&P 500 index options). Next, we regress daily excess returns over a 1-year rolling window on the excess market return and the high-low vol-of-vol factor or the S\&P 500 vol-of-vol factor. We use the following functional form:

$$
r_{i, \tau}-r_{\tau}^{f}=\alpha+\beta_{i t}^{F} F_{\tau}+\beta_{i t-1}^{F} F_{\tau-1}+\beta_{i t}^{M}\left(r_{\tau}^{M}-r_{\tau}^{f}\right)+\beta_{i t-1}^{M}\left(r_{\tau-1}^{M}-r_{\tau-1}^{f}\right),
$$

where $t$ is the last trading day of each month in our sample, $\tau \approx\{t-1, \ldots, t-250\}$ are all trading days in the 1-year window preceding day $t, r_{i, t}$ is the daily return of stock $i, r_{\tau}^{f}$ is the risk-free rate, $r_{\tau}^{M}$ is the equity market return, and $\beta_{i t}^{F}$ and $\beta_{i t-1}^{F}$ capture firm $i$ 's exposure to 1 of the 2 factors, $F_{\tau}$. We include the first lag $\beta_{i t-1}^{F}$ to control for potential issues of infrequent trading (Dimson (1979)). In the regressions we require at least 12 degrees of freedom when only a very few $r_{i, \tau}$ are available. Next, we use the sum $\beta_{i t}^{F}+\beta_{i t-1}^{F}$ as an instrument for the future expected factor loadings (i.e., vol-of-vol betas).

If vol-of-vol is priced as a factor, a stock with a high vol-of-vol factor loading should have a different average return than a stock with a low vol-of-vol factor loading. To examine this idea, Panel A of Table 7 presents average excess returns of 5 portfolios formed after sorting stocks each month on the vol-of-vol factor loading. To facilitate comparison, the top row labeled "Vol-of-vol characteristic" restates the single-sort result on the vol-of-vol characteristic from Table 3. The rows labeled "High-low vol-of-vol beta" and "S\&P 500 vol-of-vol beta" show that the decrease in excess returns over the high-low vol-of-vol beta quintiles is less negative than the decrease over the vol-of-vol characteristic quintiles ("High-low vol-of-vol beta") or positive ("S\&P 500 vol-of-vol beta"). The highlow differences in excess returns and 4-factor alphas are statistically insignificant with $t$-statistics between -1.26 and +0.94 . Hence, single sorts fail to indicate a significant factor explanation for the vol-of-vol effect.

The sort on the vol-of-vol beta may correlate with the vol-of-vol characteristic, which may increase noise in the resulting portfolio returns. Therefore, we proceed by following the approach used by Daniel and Titman (1997), Daniel, Titman, and Wei (2001), and Davis, Fama, and French (2000). We form 25 portfolios by equally dividing each of the vol-of-vol quintiles into 5 value-weighted 
TABLE 7

\section{Empirical Test of Vol-of-Vol as a Priced Risk Factor}

Table 7 presents test results on whether exposures to a vol-of-vol factor explain the vol-of-vol effect during our sample period from Jan. 1996 to Oct. 2014. Vol-of-vol is past month's volatility of option-implied volatility (IV), standardized by average IV (see Section II). IV is calculated from at-the-money call and put options with maturity closest to 30 days. Each month we sort stocks into quintiles on the basis of vol-of-vol using a 1-trading-day implementation lag and valueweighting stocks in each portfolio. We construct a vol-of-vol factor either from the returns on the high-low vol-of-vol portfolio ("High-low vol-of-vol beta") or by computing vol-of-vol from Standard \& Poor's (S\&P) 500 index options ("S\&P 500 vol-of-vol beta"). Next, requiring at least 12 degrees of freedom, we measure exposure to either vol-of-vol factor as the sum of the coefficients $\beta_{i t}^{F}+\beta_{i t-1}^{F}$ from the following regression run over the past year:

$$
r_{i, \tau}-r_{\tau}^{f}=\alpha+\beta_{i t}^{F} F_{\tau}+\beta_{i t-1}^{F} F_{\tau-1}+\beta_{i t}^{M}\left(r_{\tau}^{M}-r_{\tau}^{f}\right)+\beta_{i t-1}^{M}\left(r_{\tau-1}^{M}-r_{\tau-1}^{f}\right),
$$

where $t$ is the last trading day of each month in our sample, $\tau \approx\{t-1, \ldots, t-250\}$ are all trading days in the 1-year window preceding day $t, r_{i, t}$ is the daily return of stock $i, r_{\tau}^{f}$ is the risk-free rate, $r_{\tau}^{M}$ is the equity market return, and $\beta_{i t}^{F}$ and $\beta_{i t-1}^{F}$ capture firm $i$ 's exposure to 1 of the 2 factors $F_{\tau}$. Panel A reports the results of the single-sort portfolio analysis. Each month we sort stocks in ascending order into quintile portfolios ("Low," "2," "3," "4," and "High") on the basis of the vol-of-vol characteristic as in Table 3 ("Vol-of-vol characteristic"), or on the basis of the estimated exposure to the aggregate volof-vol factor $\beta_{i t}^{F}+\beta_{i t-1}^{F}$ ("High-low vol-of-vol beta" or "S\&P 500 vol-of-vol beta"). Panel A reports average excess returns of each portfolio over the subsequent month, as well as the difference in returns between the high portfolio and the low portfolio ("High-Low"). The columns labeled "High-Low (4F Alpha)" present the difference in 4-factor alphas between the high portfolio and the low portfolio. Panel B reports the results of the double-sort analysis. For the rows labeled "Vol-of-Vol Factor Performance (Neutral Vol-of-Vol Characteristic)," We sort stocks each month into quintile portfolios on the basis of the vol-of-vol characteristic, each of the resulting quintiles into 5 additional portfolios based on one of the vol-of-vol betas, and then average across the 5 characteristic portfolios within each beta portfolio. For the rows labeled "Vol-of-Vol Characteristic Performance (Neutral Vol-of-Vol Factor)," we sort stocks each month into quintile portfolios on the basis of 1 of the vol-of-vol betas, each of the resulting quintiles into 5 additional portfolios based on the vol-of-vol characteristic, and then average across the 5 beta portfolios within each characteristic portfolio. The rows labeled "High-low vol-of-vol beta" and "S\&P 500 vol-of-vol beta" present for each respective factor definition the monthly excess return on each of the resulting portfolios, and the difference in excess returns and 4-factor alphas between the high portfolio and the low portfolio. The rows labeled "Portfolio Characteristics" report the average ex ante high-low vol-of-vol beta, the average ex post high-low vol-of-vol beta, and the average vol-of-vol characteristic of each vol-of-vol beta quintile. Panel $\mathrm{C}$ reports the results for Europe of a single-sort portfolio analysis similar to Panel A, where the E.U. vol-of-vol factor is measured by either the returns on the high-low vol-of-vol portfolio constructed from European stocks or the vol-of-vol calculated from the EURO STOXX 50 index. We report the Newey-West (1987) corrected $t$-statistics in parentheses. * ${ }^{* \star}$, and ${ }^{* \star *}$ indicate significance at the $10 \%, 5 \%$, and $1 \%$ levels, respectively.

\begin{tabular}{|c|c|c|c|c|c|c|c|}
\hline \multirow{2}{*}{$\frac{\text { Statistics }}{\text { Panel A. Single-Sort Analysis }}$} & \multirow[t]{2}{*}{ Low } & \multirow[t]{2}{*}{2} & \multirow[t]{2}{*}{3} & \multirow[t]{2}{*}{4} & \multirow[t]{2}{*}{ High } & \multirow[t]{2}{*}{ High-Low } & \multirow[t]{2}{*}{$\begin{array}{l}\text { High-Low } \\
\text { (4F Alpha) } \\
\end{array}$} \\
\hline & & & & & & & \\
\hline Vol-of-vol characteristic & $\begin{array}{l}0.81^{\star \star \star} \\
(2.61)\end{array}$ & $\begin{array}{l}0.61^{\star \star} \\
(1.99)\end{array}$ & $\begin{array}{l}0.68^{\star \star} \\
(2.06)\end{array}$ & $\begin{array}{c}0.4 \\
(1.19)\end{array}$ & $\begin{array}{c}0.12 \\
(0.32)\end{array}$ & $\begin{array}{l}-0.69^{\star \star \star} \\
(-2.96)\end{array}$ & $\begin{array}{l}-0.60^{\star \star \star} \\
(-2.62)\end{array}$ \\
\hline High-low vol-of-vol beta & $\begin{array}{l}0.77^{\star \star} \\
(2.35)\end{array}$ & $\begin{array}{l}0.67^{\star \star} \\
(2.24)\end{array}$ & $\begin{array}{l}0.65^{\star \star} \\
(2.08)\end{array}$ & $\begin{array}{c}0.56 \\
(1.44)\end{array}$ & $\begin{array}{c}0.18 \\
(0.32)\end{array}$ & $\begin{array}{c}-0.59 \\
(-1.26)\end{array}$ & $\begin{array}{c}-0.47 \\
(-1.11)\end{array}$ \\
\hline S\&P 500 vol-of-vol beta & $\begin{array}{c}0.35 \\
(0.80)\end{array}$ & $\begin{array}{c}0.60^{*} \\
(1.83)\end{array}$ & $\begin{array}{l}0.69^{\star \star} \\
(2.32)\end{array}$ & $\begin{array}{c}0.55^{*} \\
(1.83)\end{array}$ & $\begin{array}{c}0.62 \\
(1.52)\end{array}$ & $\begin{array}{c}0.26 \\
(0.94)\end{array}$ & $\begin{array}{c}0.29 \\
(0.94)\end{array}$ \\
\hline \multicolumn{8}{|l|}{ Panel B. Double-Sort Analysis } \\
\hline \multicolumn{8}{|c|}{ Vol-of-Vol Factor Performance (Neutral Vol-of-Vol Characteristic) } \\
\hline High-low vol-of-vol beta & $\begin{array}{c}0.77^{\star \star} \\
(2.24)\end{array}$ & $\begin{array}{l}0.65^{\star \star} \\
(2.24)\end{array}$ & $\begin{array}{c}0.51 \\
(1.54)\end{array}$ & $\begin{array}{c}0.52 \\
(1.28)\end{array}$ & $\begin{array}{c}0.26 \\
(0.44)\end{array}$ & $\begin{array}{c}-0.51 \\
(-1.02)\end{array}$ & $\begin{array}{l}-0.35 \\
(-0.81)\end{array}$ \\
\hline S\&P 500 vol-of-vol beta & $\begin{array}{c}0.34 \\
(0.76)\end{array}$ & $\begin{array}{l}0.66^{\star \star} \\
(1.99)\end{array}$ & $\begin{array}{c}0.52^{\star} \\
(1.68)\end{array}$ & $\begin{array}{c}0.58^{*} \\
(1.88)\end{array}$ & $\begin{array}{c}0.58 \\
(1.39)\end{array}$ & $\begin{array}{c}0.24 \\
(0.89)\end{array}$ & $\begin{array}{c}0.24 \\
(0.83)\end{array}$ \\
\hline \multicolumn{8}{|c|}{ Vol-of-Vol Characteristic Performance (Neutral Vol-of-Vol Factor) } \\
\hline High-low vol-of-vol beta & $\begin{array}{l}0.73^{\star \star} \\
(2.06)\end{array}$ & $\begin{array}{c}0.68^{*} \\
(1.94)\end{array}$ & $\begin{array}{r}0.69^{\star} \\
(1.86)\end{array}$ & $\begin{array}{c}0.46 \\
(1.28)\end{array}$ & $\begin{array}{c}0.30 \\
(0.79)\end{array}$ & $\begin{array}{l}-0.43^{\star \star \star} \\
(-2.75)\end{array}$ & $\begin{array}{l}-0.37^{\star \star} \\
(-2.13)\end{array}$ \\
\hline S\&P 500 vol-of-vol beta & $\begin{array}{l}0.75^{\star \star} \\
(2.24)\end{array}$ & $\begin{array}{l}0.83^{\star \star} \\
(2.51)\end{array}$ & $\begin{array}{r}0.59^{\star} \\
(1.70)\end{array}$ & $\begin{array}{c}0.41 \\
(1.07)\end{array}$ & $\begin{array}{c}0.05 \\
(0.12)\end{array}$ & $\begin{array}{l}-0.71^{\star \star \star} \\
(-3.14)\end{array}$ & $\begin{array}{l}-0.59^{\star \star *} \\
(-2.61)\end{array}$ \\
\hline \multicolumn{8}{|l|}{ Portfolio Characteristics } \\
\hline Ex ante vol-of-vol beta & -0.59 & -0.19 & 0.07 & 0.32 & 0.85 & 1.44 & \\
\hline Ex post vol-of-vol beta & -0.26 & -0.09 & -0.01 & 0.15 & 0.46 & 0.72 & \\
\hline Vol-of-vol characteristic & 0.09 & 0.09 & 0.09 & 0.09 & 0.09 & 0.00 & \\
\hline \multicolumn{8}{|c|}{ Panel C. Country-Neutral Single Sorts: Europe } \\
\hline $\begin{array}{l}\text { High-low vol-of-vol beta } \\
\text { (European stocks) }\end{array}$ & $\begin{array}{c}0.31 \\
(0.44)\end{array}$ & $\begin{array}{c}0.68 \\
(1.14)\end{array}$ & $\begin{array}{c}0.58 \\
(1.04)\end{array}$ & $\begin{array}{c}0.66 \\
(1.08)\end{array}$ & $\begin{array}{l}-0.02 \\
(-0.03)\end{array}$ & $\begin{array}{l}-0.33 \\
(-0.90)\end{array}$ & $\begin{array}{l}-0.43 \\
(-1.19)\end{array}$ \\
\hline $\begin{array}{l}\text { EURO STOXX } 50 \text { vol-of-vol } \\
\text { beta }\end{array}$ & $\begin{array}{c}0.63 \\
(0.80)\end{array}$ & $\begin{array}{c}0.53 \\
(0.77)\end{array}$ & $\begin{array}{c}0.43 \\
(0.71)\end{array}$ & $\begin{array}{c}0.28 \\
(0.44)\end{array}$ & $\begin{array}{l}0.31 \\
(0.49)\end{array}$ & $\begin{array}{l}-0.32 \\
(-0.81)\end{array}$ & $\begin{array}{l}-0.47 \\
(-1.05)\end{array}$ \\
\hline
\end{tabular}


portfolios based on the estimated vol-of-vol factor loadings. Next, within each vol-of-vol factor loading quintile we average across the vol-of-vol characteristic portfolios. This results in sets of portfolios that consist of stocks with similar vol-of-vol characteristics but different loadings on the vol-of-vol factor. If the volof-vol result reflects exposures to a systematically priced risk factor, a stock with a high vol-of-vol factor loading should have a lower average return than a stock with a low vol-of-vol factor loading but a similar vol-of-vol characteristic.

Panel B of Table 7 reports the results in the rows labeled "Vol-of-vol factor performance (neutral vol-of-vol characteristic)." As we move from a low to a high portfolio, we are moving from portfolios with low average loadings on one of the vol-of-vol factors to portfolios with high loadings. However, high-low differences in excess returns and alphas are not significant, with $t$-statistics of -1.02 and -0.81 , respectively, for the high-low vol-of-vol factor, and $t$-statistics of +0.89 and +0.83 , respectively, for the S\&P 500 vol-of-vol factor. This is consistent with the result of the single portfolio sorts reported in Panel A. The existence of a systematically priced vol-of-vol risk factor is not statistically confirmed once the vol-of-vol characteristic is controlled for.

In addition, we reverse the preceding approach by first creating portfolios based on the vol-of-vol factor, then creating portfolios based on the vol-of-vol characteristic, and finally averaging across the vol-of-vol factor portfolios within each vol-of-vol characteristic portfolio. The returns on the resulting portfolios are reported in the rows labeled "Vol-of-vol characteristic performance (neutral vol-of-vol factor)." For both vol-of-vol factor definitions, high-low differences in excess returns and alphas remain highly significant, with $t$-statistics ranging between -2.13 and -3.14 . Hence, the impact of the vol-of-vol characteristic on stock returns is not driven by stock-level exposures to an aggregate vol-of-vol factor.

Particularly for high-low vol-of-vol beta, the insignificant link between the vol-of-vol loadings and returns potentially reflects the fact that ex ante loadings are weak predictors of ex post loadings. However, the bottom half of Panel $\mathrm{B}$ in Table 7 shows that both average ex ante vol-of-vol factor loadings ("Ex ante vol-of-vol beta") and average ex post factor loadings ("Ex post vol-of-vol beta") increase monotonically across the portfolios. This indicates that the preceding method does achieve considerable dispersion in the ex post factor loadings. Furthermore, the last row ("Vol-of-vol characteristic") verifies that this procedure causes little to no variation in the vol-of-vol characteristic. Hence, our sorting procedure produces substantial variation in the vol-of-vol factor loadings that is independent of the vol-of-vol characteristic. ${ }^{12}$

We note that even though we cannot confirm econometrically that the volof-vol effect is explained by factor exposures, the decrease in excess returns over the high-low vol-of-vol beta quintiles in Panel A of Table 7 is nearly monotonic.

\footnotetext{
${ }^{12}$ Furthermore, we double-check the predictive power of the ex ante vol-of-vol betas by regressing excess returns on the high-low characteristic-controlled vol-of-vol beta portfolios on the contemporaneous market and vol-of-vol factors. This yields a vol-of-vol factor loading of 0.91 with a $t$-statistic of 6.42 .
} 
This makes us cautious to dismiss the existence of a systematically priced vol-ofvol risk factor. However, to the extent that such a factor exists, it further weakens after controlling for the vol-of-vol characteristic in Panel B. Regardless of whether a vol-of-vol factor exists, Table 7 shows that its existence does not challenge the results in this article about the vol-of-vol characteristic. Furthermore, we verify that the preceding results are robust to sample and estimation choices, as they are comparable when using a monthly rather than annual estimation window, using the Chicago Board Options Exchange (CBOE) Volatility Index (VIX) index rather than ATM S\&P 500 index options, constructing an equal-weighted or value-weighted vol-of-vol factor, constructing equal-weighted or value-weighted portfolios, or including size, value, and/or momentum factors when estimating the vol-of-vol factor betas. Moreover, if we replace predictive by contemporaneous betas we obtain comparable results.

We repeat the vol-of-vol factor approach for our sample of European stocks to further examine whether vol-of-vol is priced as a risk factor. We would ideally repeat the characteristic-factor double sort for Europe. However, important between-country differences exist that need be neutralized, and doing so requires a country-characteristic-factor triple sort for which the number of European stocks is too small. Instead, we report country-neutral single sorts for 2 European volof-vol factors, measured using either returns on the high-low vol-of-vol portfolio constructed from European stocks or vol-of-vol calculated from options on the EURO STOXX 50 index. This complements the country-neutral sort on the vol-of-vol characteristic in Section III.E. In Panel C of Table 7, sorting on the 2 European vol-of-vol factor loadings yields results that are insignificant, as for the United States. The high-low returns are -0.43 and -0.47 , respectively, with $t$-statistics of 1.19 and 1.05. Hence, we do not find a vol-of-vol factor in Europe.

\section{Why Is the Vol-of-Vol Effect Negative?}

The preceding results indicate that uncertainty about risk, as measured by vol-of-vol, robustly and negatively predicts stock returns in the United States and Europe. Furthermore, the negative vol-of-vol effect is primarily driven by firmlevel vol-of-vol as a stock characteristic, rather than by exposures to an aggregate vol-of-vol factor. A natural question is: Why does higher uncertainty about risk leads to lower stock returns? Two possible explanations for the negative vol-of-vol effect are: i) investors may care about stock-level uncertainty about risk, have a preference for this kind of uncertainty, and be willing to pay a premium for betting on highly uncertain events, and ii) investors may care about stock-level uncertainty about risk and are sufficiently heterogeneous in their uncertainty preferences or expectations. Both have been proposed by prior experimental and theoretical work on ambiguity, which links well to uncertainty about risk. ${ }^{13}$ Ambiguity is present if not only the probability distribution of returns matters but also variation in the probability assessment itself (see Ellsberg (1961)).

\footnotetext{
${ }^{13}$ For example, Klibanoff et al. (2005) argue that a 2-stage utility representation captures ambiguity, and Cubitt et al. (2012) and Conte and Hey (2013) show experimentally that 2-stage utility representation is effective in describing "Ellsbergian" choices (i.e., decision making under ambiguity).
} 
With regard to the first explanation, although many studies find different degrees of ambiguity aversion in replicating Ellsberg's (1961) original thought experiment, different results are found in applied settings. For instance, Wakker, Timmermans, and Machielse (2007) find that ambiguity-loving behavior is more prevalent than ambiguity aversion in a field experiment with a financial context, and Chen, Katuscak, and Ozdenoren (2007) find ambiguity-loving behavior in a financial bidding context. Furthermore, Abdellaoui, Baillon, Placido, and Wakker (2011) find that attitudes toward ambiguity vary over the sources from which it stems. For instance, Heath and Tversky (1991) argue that people tend to possess ambiguity-loving preferences if they feel more knowledgeable, competent, familiar, or experienced about the decision. Dimmock, Kouwenberg, Mitchell, and Peijnenburg (2013) show that people display ambiguity-seeking behavior for low-probability gain events. In a context similar to ours, Brenner and Izhakian (2012) empirically find that market-level ambiguity negatively predicts returns and argue that investors are ambiguity lovers because there is some chance of a loss.

With regard to the second explanation, heterogeneity in ambiguity preferences is demonstrated in several experiments (Ahn et al. (2014), Halevy (2007), and Bossaerts et al. (2010)) and seems a plausible assumption in our crosssectional study. Consistent with the direction of the vol-of-vol effect, Chapman and Polkovnichenko (2009) argue that the premium for ambiguity monotonously decreases the more investors differ in their ambiguity attitude aversion, and that this also affects their willingness to participate in risky asset markets. Theoretical work (e.g., Dow and Werlang (1992), Easley and O'Hara (2009)) and experimental evidence (e.g., Bossaerts et al. (2010)) also demonstrate that if an investor's ambiguity aversion is sufficiently high, she will not hold an ambiguous asset. As a consequence, ambiguous assets may be held, and priced, only by investors with a sufficiently optimistic view on (or low aversion against) ambiguity and therefore require lower ambiguity premiums. Experimental evidence for this idea can be found in Bossaerts et al. (2010), and Cao et al. (2005) present empirical evidence on limited participation and stock returns based on microeconomic surveys and stock market data from 7 countries. The models in these papers ascribe the negative link between ambiguity and equity prices to limited investor participation in the stock market.

The limited participation phenomenon is similar in spirit to the idea that negative returns arise when the most pessimistic investors are kept out of the market because of short-sale constraints (Miller (1977)), for which strong empirical evidence exists (see Diether et al. (2002); we return to this in Section VI.C). Another analogy is the "clientele effect," as studied by, for example, Amihud and Mendelson (1986) and Beber, Driessen, and Tuijp (2011), which posits different types of investors with different expected holding periods. These papers find that each type of investor trades assets with different relative spreads. In a similar vein, Bossaerts et al. (2010) conjecture that heterogeneity in ambiguity preferences may explain the value effect if value stocks are "pure risk" securities and growth stocks "ambiguous" securities. 
Empirically examining both explanations would require information on the preferences and expectations of all individual shareholders for each individual stock. Clearly, these data are unavailable and we cannot fully identify or distinguish these channels. However, we may observe limited participation by uncertainty-averse investors from decreased trading activity. More specifically, limited participation implies a smaller investor base for stocks with high uncertainty about risk, which is likely reflected in lower future trading activity in these stocks. If limited participation explains the vol-of-vol effect, higher vol-of-vol stocks may have not only lower future returns but also lower trading activity over the next month.

We run Fama-MacBeth (1973) regressions to explore the effect of vol-ofvol on next month's trading activity or next month's change in trading activity. We proxy trading activity by turnover, (natural $\log$ ) stock volume, dollar volume, and option volume. However, we report regression estimates only for turnover and the natural $\log$ of stock volume because the results are very similar for the other measures. To control for the strongly persistent nature of trading activity, we add a lag of the dependent variable to our list of regressors. In addition, we control for the most important drivers of trading activity, that is, beta, book-to-market, size, momentum, short-term reversal, idiosyncratic risk, Amihud (2002) liquidity, forecast dispersion, and a dummy related to whether earnings are reported. Our results are similar when we include other variables from Tables 2 and 4.

Table 8 conveys how the previously discussed cross-sectional differences in vol-of-vol relate to future trading activity. Regardless of how we measure trading activity, vol-of-vol has a clear and strong negative impact on future trading activity in each regression, with $t$-values of 16 or higher. ${ }^{14}$ Higher vol-of-vol stocks are associated not only with lower future levels of turnover and volume, but also with a larger future decrease in turnover and volume. On average, stocks with a vol-ofvol of 1 standard deviation above the cross-sectional mean have negative changes in future turnover and volume of about $5 \%$ and $1 \%$, respectively. Hence, higher levels of uncertainty about risk are followed by lower future trading activity, as well as larger future decreases in trading activity.

The results from Table 8 suggest that uncertainty about risk significantly affects financial markets not only in terms of expected stock returns, but also in terms of future trading activity. With trading activity proxying for stock market participation, this result is consistent with Cao et al. (2005), Chapman and Polkovnichenko (2009), and Bossaerts et al. (2010). An increase in vol-of-vol seems to decrease future investor participation. These results are in line with an explanation based on investors who are heterogeneous in their preferences and expectations regarding uncertainty about risk.

\footnotetext{
${ }^{14}$ Note that these results stand in contrast to Table 2, which shows that vol-of-vol is positively related to contemporaneous turnover. Most remaining coefficients have the expected sign except that the natural $\log$ of size is positively related to volume but negatively related to turnover, perhaps because trading volume does not differ as much between large and small firms as market capitalization does. Beta is positively related to turnover, which can be reconciled with the theories in Hong and Sraer (2012) and Frazzini and Pedersen (2014).
} 


\section{Alternative Interpretations}

\section{A. Does Vol-of-Vol Relate to Exposures to Stochastic Volatility and Jump Risk?}

Section III shows that the vol-of-vol effect persists after controlling for the spread between IV and realized volatility or option volatility skew measures. This indicates that the vol-of-vol effect is not explained by a stock-level volatility or jump risk premium. Also, such a stock-level volatility risk premium is not easily linked to the impact of vol-of-vol on turnover documented in Section V. However, as high vol-of-vol indicates increased IV dynamics, the impact of the vol-of-vol characteristic on stock returns might simply capture a compensation for systematic stochastic volatility risk or jump risk (e.g., Ang, Hodrick, et al. (2006), Cremers et al. (2015)).

To evaluate whether systematic stochastic volatility and jump risk exposures explain our results, we use the first differences in the CBOE VIX as proxies for

\section{TABLE 8}

Vol-of-Vol and Future Trading Activity

Table 8 presents coefficient estimates from monthly Fama-MacBeth (1973) regressions of turnover in Panel A and volume in Panel B, either in levels or in first differences, between month $t$ and month $t+1$ against a constant, vol-of-vol, the first lag of the dependent variable, and a series of stock characteristics, all measured at the end of month $t$ over our sample period from Jan. 1996 to Oct. 2014. The variable definitions are provided in the Appendix. Vol-of-vol is past month's volatility of option-implied volatility (IV), standardized by average IV (see Section II). IV is calculated from at-the-money call and put options with maturity closest to 30 days. We report the Newey-West (1987) corrected $t$-statistics in parentheses. ${ }^{*}, * *$, and ${ }^{* * *}$ indicate significance at the $10 \%, 5 \%$, and $1 \%$ levels, respectively.

$\underline{\text { Panel A. Turnover }}$

Variable
Constant
VOL_OF_VOL

Dependent variable $(t-1, t)$

BETA

BOOK_TO_MARKET

$\ln (\mathrm{SIZE})$

MOMENTUM

SHORT_TERM_REVERSAL

IDIOSYNC_VOLATILITY

AMIHUD_ILLIQUIDITY

FORECAST_DISPERSION

Earnings reported (0/1)

OPTION_BID_ASK_SPREAD

Adj. $R^{2}$

No. of obs.
TURNOVER $(t, t+1)$

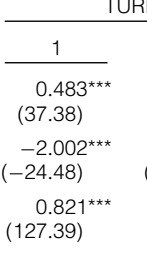

$\frac{2}{0.488^{\star \star \star}}$
$(18.98)$
$-1.907^{\star \star \star}$
$(-24.43)$
$0.792^{\star \star \star}$
$(122.24)$
$0.117^{\star \star \star}$
$(22.53)$
$0.019^{\star \star}$
$(2.47)$
$-0.015^{\star \star \star}$
$(-5.29)$
$<0.001$
$(0.04)$
$-0.106^{\star \star \star}$
$(-6.15)$
$(-6.15)$

\begin{tabular}{l} 
1) \\
\hline $0.232^{\star \star \star}$ \\
$(7.17)$ \\
$-1.612^{\star \star \star}$ \\
$(-24.44)$ \\
$0.773^{\star \star \star}$ \\
$(112.87)$ \\
$0.081^{\star \star \star}$ \\
$(15.34)$ \\
$0.034^{\star \star \star}$ \\
$(4.90)$ \\
$-0.009^{\star \star \star}$ \\
$(-3.22)$ \\
-0.006 \\
$(-0.54)$ \\
$-0.105^{\star \star \star}$ \\
$(-6.43)$ \\
$5.869^{\star \star \star}$ \\
$(11.82)$ \\
$-11.308^{\star \star \star}$ \\
$(-9.20)$ \\
$3.277^{\star \star \star}$ \\
$(5.53)$ \\
$0.375^{\star \star \star}$ \\
$(30.81)$ \\
0.048 \\
$(1.35)$ \\
0.693 \\
233,306
\end{tabular}

\begin{tabular}{|c|c|c|}
\hline \multicolumn{3}{|c|}{$\Delta$ TURNOVER $(t, t+1)$} \\
\hline 4 & 5 & 6 \\
\hline $\begin{array}{l}0.112^{\star \star \star} \\
(6.26)\end{array}$ & $\begin{array}{l}0.132^{\star \star \star} \\
(4.82)\end{array}$ & $\begin{array}{l}0.223^{\star \star \star} \\
(7.18)\end{array}$ \\
\hline $\begin{array}{l}-1.230^{\star \star \star} \\
(-16.43)\end{array}$ & $\begin{array}{l}-1.216^{\star \star \star} \\
(-17.07)\end{array}$ & $\begin{array}{l}-0.976^{\star \star \star} \\
(-16.89)\end{array}$ \\
\hline \multirow[t]{11}{*}{$\begin{array}{l}-0.356^{\star \star \star} \\
(-62.43)\end{array}$} & $\begin{array}{l}-0.360^{\star \star \star *} \\
(-68.85)\end{array}$ & $\begin{array}{l}-0.349^{\star \star \star} \\
(-74.94)\end{array}$ \\
\hline & $\begin{array}{l}-0.023^{\star \star} \\
(-2.44)\end{array}$ & $\begin{array}{l}0.020^{\star \star \star} \\
(2.66)\end{array}$ \\
\hline & $\begin{array}{c}0.011 \\
(1.29)\end{array}$ & $\begin{array}{l}-0.009 \\
(-1.25)\end{array}$ \\
\hline & $\begin{array}{l}<0.001 \\
(0.15)\end{array}$ & $\begin{array}{l}-0.014^{\star \star \star} \\
(-5.14)\end{array}$ \\
\hline & $\begin{array}{l}-0.049^{\star \star \star} \\
(-4.14)\end{array}$ & $\begin{array}{l}-0.034^{\star \star \star} \\
(-3.11)\end{array}$ \\
\hline & $\begin{array}{l}-0.171^{\star \star \star} \\
(-8.82)\end{array}$ & $\begin{array}{l}-0.149^{\star \star \star} \\
(-7.77)\end{array}$ \\
\hline & & $\begin{array}{l}-7.121^{\text {}} \\
(-12.91)\end{array}$ \\
\hline & & $\begin{array}{l}4.144^{\star \star \star} \\
(2.90)\end{array}$ \\
\hline & & $\begin{array}{l}-0.629 \\
(-1.04)\end{array}$ \\
\hline & & $\begin{array}{l}0.366^{\star \star \star} \\
(31.49)\end{array}$ \\
\hline & & $\begin{array}{l}-0.004 \\
(-0.12)\end{array}$ \\
\hline $\begin{array}{r}0.147 \\
233,295\end{array}$ & $\begin{array}{r}0.170 \\
233,295\end{array}$ & $\begin{array}{r}0.222 \\
233,295\end{array}$ \\
\hline
\end{tabular}

(continued on next page) 


\begin{tabular}{|c|c|c|c|c|c|c|}
\hline \multicolumn{7}{|c|}{$\begin{array}{c}\text { TABLE } 8 \text { (continued) } \\
\text { Vol-of-Vol and Future Trading Activity }\end{array}$} \\
\hline \multicolumn{7}{|l|}{ Panel B. Volume } \\
\hline & \multicolumn{3}{|c|}{$\operatorname{VOLUME}(t, t+1)$} & \multicolumn{3}{|c|}{$\Delta \operatorname{VOLUME}(t, t+1)$} \\
\hline Variable & 1 & 2 & 3 & 4 & 5 & 6 \\
\hline Constant & $\begin{array}{l}0.560^{\star \star \star} \\
(22.43)\end{array}$ & $\begin{array}{l}0.681^{\star \star \star} \\
(26.46)\end{array}$ & $\begin{array}{l}0.805^{\star \star \star} \\
(29.89)\end{array}$ & $\begin{array}{l}0.052^{\star \star \star} \\
(5.48)\end{array}$ & $\begin{array}{l}0.051^{\star \star \star} \\
(3.24)\end{array}$ & $\begin{array}{l}0.038^{\star \star} \\
(2.26)\end{array}$ \\
\hline VOL_OF_VOL & $\begin{array}{l}-1.041^{\star \star \star} \\
(-30.32)\end{array}$ & $\begin{array}{l}-0.835^{\star \star \star} \\
(-24.55)\end{array}$ & $\begin{array}{l}-0.609^{\star \star \star} \\
(-22.28)\end{array}$ & $\begin{array}{l}-0.532^{\star \star \star} \\
(-16.27)\end{array}$ & $\begin{array}{l}-0.516^{\star \star \star} \\
(-16.49)\end{array}$ & 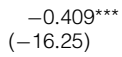 \\
\hline Dependent variable $(t-1, t)$ & $\begin{array}{l}0.960^{\star \star \star} \\
(540.55)\end{array}$ & $\begin{array}{l}0.881^{\star \star \star} \\
(253.39)\end{array}$ & $\begin{array}{l}0.845^{\star \star \star} \\
(212.53)\end{array}$ & $\begin{array}{l}-0.342^{\star \star \star} \\
(-80.99)\end{array}$ & $\begin{array}{l}-0.345^{\star \star \star} \\
(-83.93)\end{array}$ & $\begin{array}{l}-0.329^{\star \star \star} \\
(-90.65)\end{array}$ \\
\hline BETA & & $\begin{array}{l}0.044^{\star \star \star} \\
(16.82)\end{array}$ & $\begin{array}{l}0.030^{\star \star \star} \\
(13.77)\end{array}$ & & $\begin{array}{l}-0.006^{\star \star} \\
(-2.32)\end{array}$ & $\begin{array}{l}0.011^{\star \star \star} \\
(4.76)\end{array}$ \\
\hline BOOK_TO-MARKET & & $\begin{array}{l}0.015^{\star \star \star} \\
(3.90)\end{array}$ & $\begin{array}{l}0.024^{\star \star \star} \\
(7.46)\end{array}$ & & $\begin{array}{l}-0.001 \\
(-0.35)\end{array}$ & $\begin{array}{l}-0.008^{\star \star} \\
(-2.24)\end{array}$ \\
\hline $\ln (\mathrm{SIZE})$ & & $\begin{array}{l}0.090^{\star \star *} \\
(29.43)\end{array}$ & $\begin{array}{l}0.120^{\star \star \star} \\
(31.53)\end{array}$ & & $\begin{array}{r}0.001 \\
(0.78)\end{array}$ & $\begin{array}{l}-0.003^{\star \star} \\
(-2.15)\end{array}$ \\
\hline MOMENTUM & & $\begin{array}{l}-0.012^{\star \star} \\
(-2.48)\end{array}$ & $\begin{array}{l}-0.017^{\star \star \star} \\
(-3.86)\end{array}$ & & $\begin{array}{l}-0.022^{\star \star \star} \\
(-4.50)\end{array}$ & $\begin{array}{l}-0.018^{\star \star \star} \\
(-3.75)\end{array}$ \\
\hline SHORT_TERM_REVERSAL & & $\begin{array}{l}-0.070^{\star \star \star} \\
(-11.08)\end{array}$ & 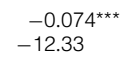 & & $\begin{array}{l}-0.082^{\text {***}}(-13.22) \\
(-22)\end{array}$ & $\begin{array}{l}-0.073^{\star \star \star} \\
(-11.93)\end{array}$ \\
\hline IDIOSYNC_VOLATILITY & & & $\begin{array}{l}3.204^{\star \star \star} \\
(11.16)\end{array}$ & & & $\begin{array}{l}-2.752^{\star \star \star \star} \\
(-12.34)\end{array}$ \\
\hline AMIHUD_ILLIQUIDITY & & & $\begin{array}{l}-2.845^{\star \star \star} \\
(-6.69)\end{array}$ & & & $\begin{array}{l}1.672^{\star \star \star} \\
(4.68)\end{array}$ \\
\hline FORECAST_DISPERSION & & & $\begin{array}{l}2.033^{\star \star \star} \\
(8.66)\end{array}$ & & & $\begin{array}{l}-0.409^{\star} \\
(-1.86)\end{array}$ \\
\hline Earnings reported $(0 / 1)$ & & & $\begin{array}{l}0.215^{\star \star \star} \\
(34.27)\end{array}$ & & & $\begin{array}{l}0.207^{\text {** }} \\
(37.45)\end{array}$ \\
\hline OPTION_BID_ASK_SPREAD & & & $\begin{array}{l}-0.401^{\star \star \star} \\
(-20.83)\end{array}$ & & & $\begin{array}{l}0.081^{\star \star \star} \\
(4.85)\end{array}$ \\
\hline $\begin{array}{l}\text { Adj. } R^{2} \\
\text { No. of obs. }\end{array}$ & $\begin{array}{r}0.919 \\
232,500\end{array}$ & $\begin{array}{r}0.924 \\
232,500\end{array}$ & $\begin{array}{r}0.930 \\
232,500\end{array}$ & $\begin{array}{r}0.137 \\
232,489\end{array}$ & $\begin{array}{r}0.156 \\
232,489\end{array}$ & $\begin{array}{r}0.222 \\
232,489\end{array}$ \\
\hline
\end{tabular}

stochastic volatility following Ang, Hodrick, et al. (2006), and the slope of the IV skew on S\&P 500 index options as the jump risk factor motivated by Yan (2011). First, we expand the 4-factor model we use previously to a 6-factor model that contains the stochastic volatility factor and the aggregate jump risk factor, and then single-sort on vol-of-vol. The results in Panel A of Table 9 (as well as unreported equal-weighted results) indicate that adding jump and volatility risk factors does not materially change $4 \mathrm{~F}$ alphas or their corresponding $t$-statistics.

Second, we estimate jump and volatility risk factor loadings at the individual stock level following Cremers et al. (2015). The procedure to construct jump risk and volatility risk factor loadings is similar to the procedure for constructing the vol-of-vol factor outlined in Section IV. Specifically, we regress each stock's daily excess returns against the daily returns on the jump risk or volatility risk factor, the market factor, and their first lags to control for infrequent trading (Dimson (1979)). Subsequently, we double-sort stocks into 25 portfolios based on the estimated volatility risk or jump risk loadings over the current month and vol-of-vol at the beginning of the current month to construct vol-of-vol portfolios with similar stochastic volatility or jump risk exposure.

Panel B of Table 9 presents the results for each vol-of-vol quintile and the high-low portfolio, expressed in average excess returns and $4 \mathrm{~F}$ alphas. We find that high-low differences in returns (4F alphas) remain economically important 
TABLE 9

Can Volatility Risk Exposure or Jump Risk Exposure Explain Low Returns on High Vol-of-Vol Stocks?

Table 9 reports the vol-of-vol effect over our sample period from Jan. 1996 to Oct. 2014, after controlling for exposures to jump risk and volatility risk. Vol-of-vol is past month's volatility of option-implied volatility (IV), standardized by average IV (see Section II). IV is calculated from at-the-money call and put options with maturity closest to 30 days. We proxy aggregate volatility risk by the first daily differences in the Chicago Board Options Exchange (CBOE) Volatility Index (VIX), and aggregate jump risk by the change in the slope of the implied volatility skew of Standard \& Poor's (S\&P) 500 index options, as defined in the Appendix. We calculate firm-specific exposures to these factors as discussed in Section VI.A. Panel A reports 6-factor alphas after augmenting the 4-factor model by the volatility risk factor and the jump risk factor. Panel B repeats the double-sorting analysis in Table 4, where we first sort stocks in ascending order into quintile portfolios on the basis of jump risk exposure or volatility risk exposure. We use a 1-trading-day implementation lag and value weigh stocks in each portfolio. We report the Newey-West (1987) corrected $t$-statistics in parentheses. ${ }^{*},{ }^{* *}$, and ${ }^{* * *}$ indicate significance at the $10 \%, 5 \%$, and $1 \%$ levels, respectively.

Panel A. 6-Factor Alphas of Portfolios Sorted by Vol-of-Vol

\begin{tabular}{|c|c|c|c|c|c|c|}
\hline Statistics & Low & 2 & 3 & 4 & High & High-Low \\
\hline 6-factor alpha & $\begin{array}{c}0.23^{*} \\
(1.61)\end{array}$ & $\begin{array}{c}0.08 \\
(0.72)\end{array}$ & $\begin{array}{c}0.07 \\
(0.77)\end{array}$ & $\begin{array}{c}-0.06 \\
(-0.67)\end{array}$ & $\begin{array}{l}-0.43^{\star \star \star} \\
(-2.70)\end{array}$ & $\begin{array}{l}-0.66^{\star \star} \\
(-2.43)\end{array}$ \\
\hline
\end{tabular}

Panel B. Returns of Portfolios Sorted by Jump Risk or Volatility Risk and Vol-of-Vol

\begin{tabular}{|c|c|c|c|c|c|c|c|}
\hline Statistics & Low & 2 & 3 & 4 & High & High-Low & $\begin{array}{l}\text { High-Low } \\
\text { (4F Alpha) }\end{array}$ \\
\hline $\begin{array}{l}\text { Volatility risk }(\Delta \mathrm{VIX}) \\
\text { betas }\end{array}$ & $\begin{array}{l}0.74^{\star *} \\
(2.12)\end{array}$ & $\begin{array}{r}0.60^{\star} \\
(1.79)\end{array}$ & $\begin{array}{c}0.57 \\
(1.62)\end{array}$ & $\begin{array}{c}0.39 \\
(1.03)\end{array}$ & $\begin{array}{c}0.09 \\
(0.23)\end{array}$ & $\begin{array}{l}-0.64^{\star \star \star} \\
(-3.31)\end{array}$ & $\begin{array}{l}-0.57^{\star \star \star} \\
(-2.81)\end{array}$ \\
\hline $\begin{array}{l}\text { Jump risk ( } \triangle \text { OPTION_SKEW) } \\
\text { betas }\end{array}$ & $\begin{array}{l}0.81^{\star *} \\
(2.45)\end{array}$ & $\begin{array}{l}0.71^{* *} \\
(2.16)\end{array}$ & $\begin{array}{r}0.59^{*} \\
(1.69)\end{array}$ & $\begin{array}{c}0.40 \\
(1.10)\end{array}$ & $\begin{array}{c}0.18 \\
(0.45)\end{array}$ & $\begin{array}{l}-0.63^{\star * *} \\
(-2.85)\end{array}$ & $\begin{array}{l}-0.55^{\star \star \star} \\
(-2.65)\end{array}$ \\
\hline
\end{tabular}

and statistically significant after controlling for exposures to first differences in the CBOE VIX (" $\Delta$ VIX betas"), with an average value of $-0.64 \%(-0.57 \%)$ per month and a $t$-statistic of $-3.31(-2.81)$. Similarly, controlling for exposures to the change in the slope of the IV skew (" $\triangle$ OPTION_SKEW betas") continues to yield a strong vol-of-vol effect, witnessing an average high-low excess return (4F alpha) of $-0.63 \%(0.55 \%)$ per month with a $t$-statistic of $-2.85(-2.65)$. Hence, the results from Panels A and B reject an explanation of the negative volof-vol effect based on individual stocks' systematic volatility risk or jump risk exposures. ${ }^{15}$

\section{B. Does Vol-of-Vol Indicate Earnings Anomalies?}

Table 2 reveals that a seasonality effect exists, with higher vol-of-vol levels during a firm's earnings reporting month. Hence, uncertainty about risk potentially links to earnings anomalies as documented by, for example, Frazzini and Lamont (2007). To examine the extent to which the vol-of-vol effect is reflected in earnings anomalies, we take 3 approaches.

First, we examine the vol-of-vol effect for months in which firms report or do not report earnings. To this end, we forecast expected announcement months for all stocks according to the methodology of Frazzini and Lamont (2007), resulting in 2 subsets of stocks for which we either do or do not expect an earnings announcement. We subsequently form quintile portfolios based on vol-of-vol within each subset, and calculate average returns and alphas across subsets. In Table 10, the rows labeled "Stock-months: No earnings announcement" and "Stock-months:

\footnotetext{
${ }^{15}$ Our results are robust to calculating ex ante factor loadings or using a 1-month estimation window. We also obtain qualitatively similar results when we use alternative factor definitions such as the return of ATM, market-neutral straddles on S\&P 500 index options for volatility risk, and the returns of out-of-the-money index puts on the S\&P 500 for jump risk.
} 
TABLE 10

Can Earnings Anomalies Explain Low Returns on High Vol-of-Vol Stocks?

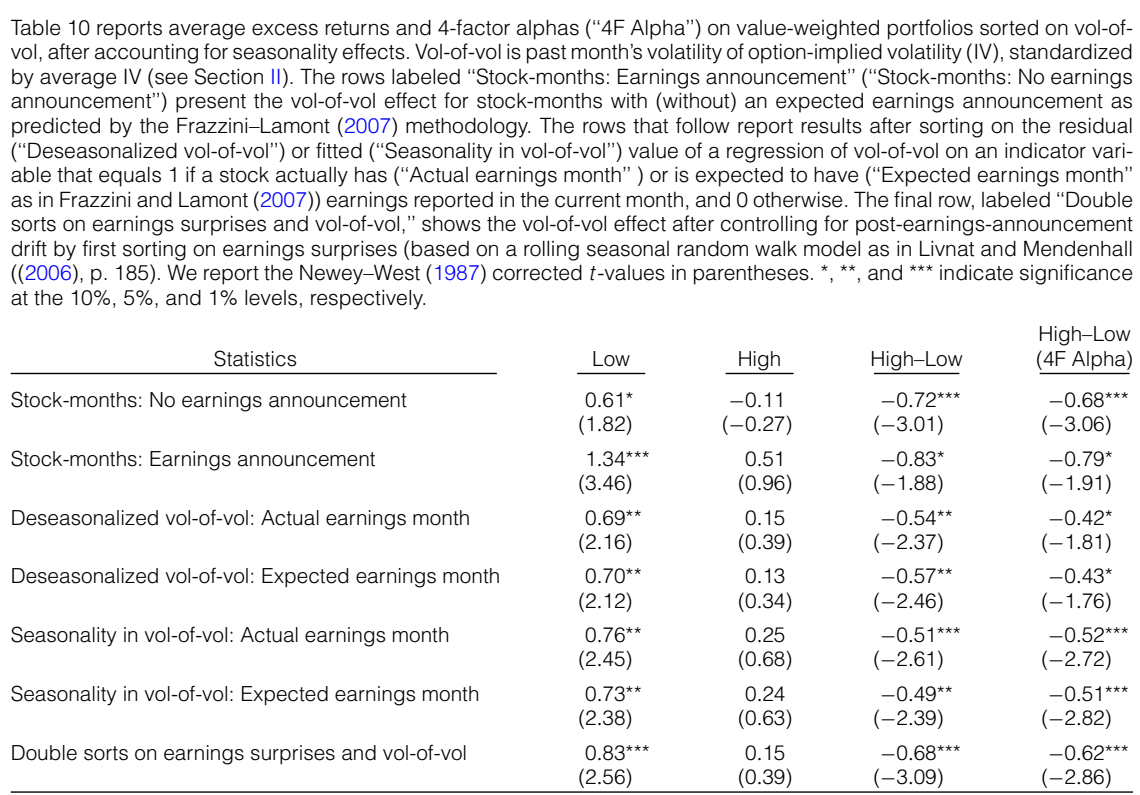

Earnings announcement" present the results. The high-low return and 4F alpha increase most for the subset of stocks expected to report earnings, suggesting that the vol-of-vol effect is stronger around earnings announcements. This confirms our earlier result from Table 1 that earnings announcements are often surrounded by considerable uncertainty about risk. However, the vol-of-vol effect remains large in magnitude and more significant when stocks are not expected to report earnings. $^{16}$

Second, to directly disentangle vol-of-vol into a seasonal and a nonseasonal component, we regress vol-of-vol against an indicator variable that equals 1 if a stock is in an earnings announcement month, and 0 otherwise. In Table 10, we do this for actual earnings months in the rows labeled "Actual earnings month" and for expected earnings months (as predicted by the Frazzini-Lamont (2007) method) in the rows labeled "Expected earnings month." We then calculate the vol-of-vol effect that is independent of earnings seasonality by replacing vol-ofvol with the residuals from this regression, and present the result in the rows labeled "Deseasonalized vol-of-vol." We perform a similar operation based on the fitted values from this regression in the rows labeled "Seasonality in vol-ofvol" and interpret this as the seasonal component of vol-of-vol. We find similar results in that, although earnings announcements are related to the vol-of-vol effect, the vol-of-vol effect remains strong and significant even after vol-of-vol is deseasonalized.

\footnotetext{
${ }^{16}$ Note that the returns are uniformly higher in earnings announcement months, which is attributable to the earnings announcement effect documented by Frazzini and Lamont (2007).
} 
Finally, a well-known earnings effect is that stock returns tend to drift in the direction of an earnings surprise after an earnings announcement (Ball and Brown (1968)). Therefore, we repeat the double-sorting procedure from Section III.C and sort stocks into quintiles based on quarterly SUEs. SUEs are calculated from the rolling seasonal random walk model in Livnat and Mendenhall (2006) and analyst earnings per share (EPS) forecasts from IBES. We subsequently form quintile portfolios based on vol-of-vol within each subset and average each vol-of-vol quintile across the SUE portfolios. It can be seen that the vol-of-vol effect remains large and significant even across vol-of-vol portfolios that are similar in terms of SUE. These results indicate that earnings seasonalities cannot fully explain the vol-of-vol effect.

\section{Does Vol-of-Vol Relate to Deviations from Fundamental Value?}

Lower future returns on stocks with higher vol-of-vol could also indicate that the prices of high vol-of-vol stocks are higher than justified by their fundamental value. For example, the negative vol-of-vol effect may reflect an optimism bias. Miller (1977) and Chen, Hong, and Stein (2001) argue that prices reflect a more optimistic valuation if short-sale constraints prevent pessimistic investors from holding a short position in a stock. In this situation, market prices rise relative to the true value of a stock when disagreement about the profitability of a stock increases, leading to negative expected returns. Because vol-of-vol may indicate disagreement about risk, the vol-of-vol effect might result from overoptimism in the presence of short-sale constraints.

To investigate this, we repeat the double-sorting procedure from Section III.C by sorting stocks into quintile portfolios based on short-sale constraints (proxied by residual institutional ownership). Next, we further sort each portfolio into quintile portfolios based on vol-of-vol. Panel A of Table 11 presents the average excess returns and 4F alphas of the resulting 25 short-sale constraints/vol-of-vol portfolios and the high-low portfolios. The vol-of-vol effect in the "High-Low" and "High-Low (4F Alpha)" columns increases monotonically with short-sale constraints. The increase is significant with a $t$-statistic of $-2.86(-2.51)$. In the "Low short-sale constraints" quintile, the vol-of-vol effect is smallest in magnitude and statistically indistinguishable from $0 .{ }^{17}$ These results suggest that the vol-of-vol effect is more pronounced among stocks held less by institutional investors, which are therefore more difficult to short. ${ }^{18}$

Nevertheless, the vol-of-vol effect remains large and statistically significant after controlling for short-sale constraints. Furthermore, Panel C of Table 4 shows that the vol-of-vol effect is also present among the largest and most liquid stocks, whereas disagreement and short-sale constraints tend to be smaller for those stocks. Finally, our sample excludes penny stocks and micro-caps so

\footnotetext{
${ }^{17}$ As an additional check (unreported), we repeat the double sort using the percentage of institutional ownership instead of residual institutional ownership, and find similar results.

${ }^{18}$ Some low vol-of-vol portfolios have positive alphas, which is not consistent with the Miller (1977) hypothesis. We should note that these alphas are no longer significant when the stocks are equal weighted or when short-sale constraints are measured alternatively by actual short interest, that is, the quantity of shares sold short (not reported to preserve space). However, the vol-of-vol effect remains present regardless of the weighting scheme or short-sales measure used.
} 
TABLE 11

Can Deviations from Fundamental Value Explain

Low Returns on High Vol-of-Vol Stocks?

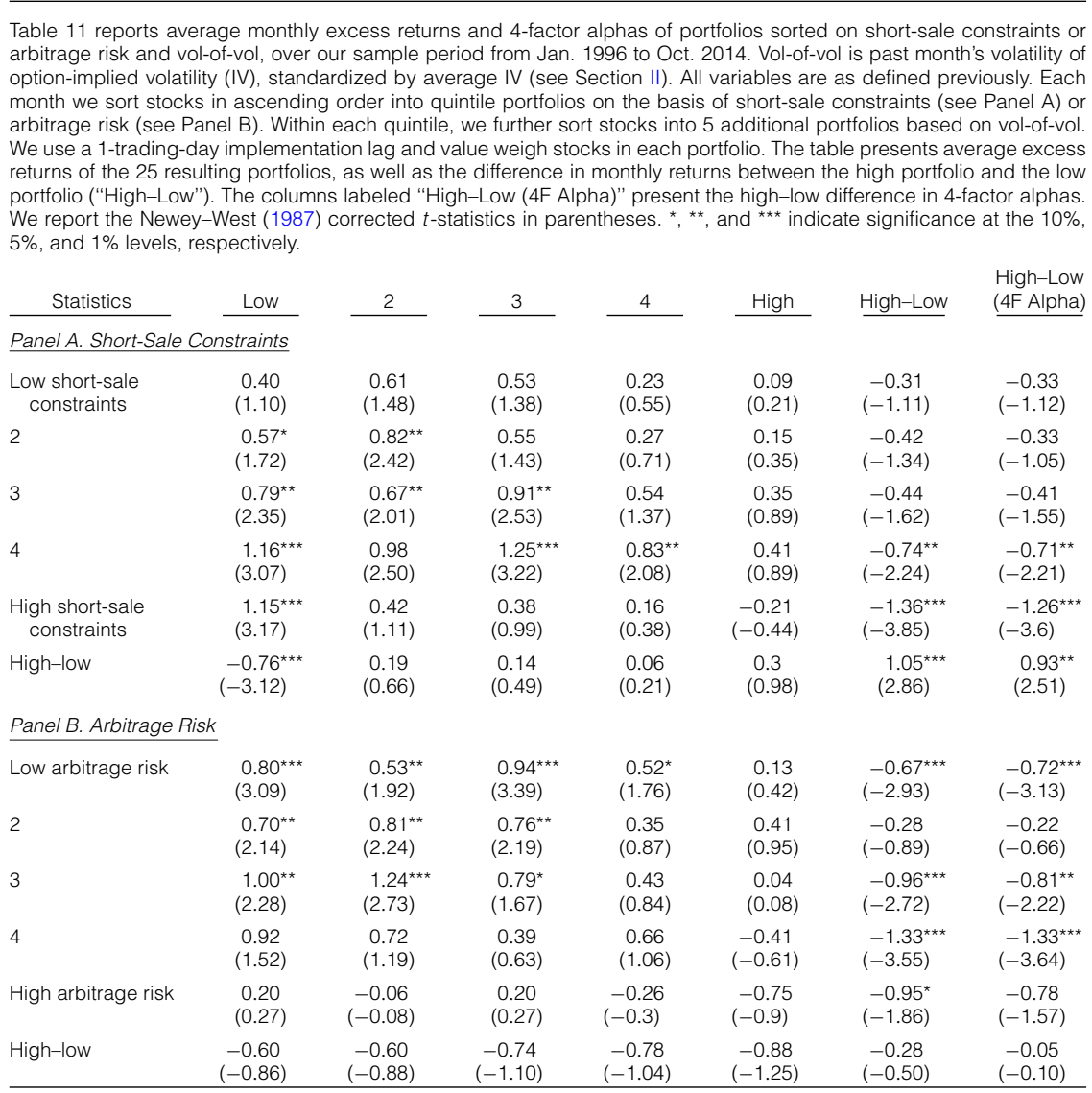

that short-sale constraints are already relatively low (D'Avolio (2002)). Hence, the vol-of-vol effect is only partially explained by optimism bias. To further test whether the vol-of-vol effect is driven by short sale constraints, we run the FamaMacBeth (1973) regressions of returns on vol-of-vol, short-sale constraints, and vol-of-vol times short-sale constraints (unreported). The coefficients on vol-of-vol and short-sale constraints remain significant but the interaction term is insignificant. This indicates that, per unit of vol-of-vol, the vol-of-vol effect does not significantly change for different levels of short-sale constraints. This is further evidence against explanations based on overoptimism in the presence of shortsale constraints.

More generally, if vol-of-vol is driven by pricing errors of any kind, we expect such errors to be larger when arbitrage is riskier. For instance, De Long, Shleifer, Summers, and Waldmann (1990) and Shleifer and Vishny (1997) argue that financial markets might not always be informationally efficient when arbitrage is risky, as arbitrage risk deters arbitrageurs from exploiting pricing errors. 
In fact, previous studies find that arbitrage risk amplifies anomalies such as bookto-market, post-earnings-announcement drift, accounting accruals, and momentum (Ali, Hwang, and Trombley (2003), Mendenhall (2004), and Mashruwala, Rajgopal, and Shevlin (2006)). We explore this mispricing-based explanation by first sorting stocks into quintile portfolios based on arbitrage risk, followed by sorting stocks into quintile portfolios based on vol-of-vol. We proxy arbitrage risk by idiosyncratic volatility, as an increase in idiosyncratic volatility generally makes arbitrage more risky and results in smaller optimal positions by arbitrageurs (Shleifer and Vishny (1997), Pontiff (2006)).

Panel B of Table 11 shows the performance of the 25 resulting portfolios and the high-low portfolios (in terms of excess returns and 4F alphas) for the arbitrage risk and vol-of-vol quintiles. ${ }^{19}$ Regardless of whether we measure performance in terms of returns or $4 \mathrm{~F}$ alphas, and use value weights or equal weights (unreported to preserve space), the vol-of-vol effect does not gradually become stronger as arbitrage risk increases. Specifically, the effect of vol-of-vol tends to be primarily significant for stocks with low or moderate arbitrage risk, whereas the vol-of-vol effect is only weakly significant (for equal-weighted returns), or not significant at all (for value-weighted returns and for equal-weighted/value-weighted 4F alphas) when arbitrage risk is the highest. This is not what mispricing-based explanations predict.

\section{Does Vol-of-Vol Relate to an Asymmetric Returns Distribution?}

Vol-of-vol might also reflect asymmetric risk patterns not captured by idiosyncratic volatility (downside) beta, skewness, or kurtosis. For example, low vol-of-vol stocks or portfolios may carry substantial downside or lower-tail risk to which investors are generally averse, and that is compensated for with higher future returns. Alternatively, high vol-of-vol stocks or portfolios may have more upside potential, which is a return property that investors generally prefer and that drives down the expected return. These asymmetries could be hidden from the portfolio sorts because only few stocks might actually realize this potential. In Table A4 in the Internet Appendix, we examine the distribution of future monthly returns in more detail and find that future stock or portfolio returns distributions of various vol-of-vol portfolios provide no evidence for an asymmetric risk-based explanation.

\section{Conclusion}

Uncertainty about risk, measured by vol-of-vol, predicts future stock returns. In terms of excess returns (4-factor alphas), high vol-of-vol stocks underperform low vol-of-vol stocks by about $8 \%(6 \%)$ per year. This effect is economically substantial, especially given the fact that our sample is by construction tilted toward larger, better investable, and (for many investors) economically more interesting stocks. For comparison, the canonical book-to-market and momentum effects range between $2 \%$ and $5 \%$ per year in our sample.

\footnotetext{
${ }^{19}$ The large insignificant returns on the high-low idiosyncratic risk portfolios turn significant when portfolio performance is expressed in 1-, 3-, or 4-factor alphas.
} 
The negative vol-of-vol effect is robust and has a distinct nature. The vol-ofvol effect survives over 20 previously documented return drivers and persists up to 24 months after portfolio formation, and the Fama-MacBeth (1973) regressions show that the vol-of-vol effect is not a combination of previously documented return drivers. Furthermore, it cannot be ascribed to industry effects or to specific subperiods or events within our sample period, it holds for a variety of vol-of-vol definitions, and it is found in value-weighted and equal-weighted quintile portfolios. Finally, the vol-of-vol effect is present in both U.S. and European stocks.

We find that vol-of-vol is primarily priced as a characteristic, rather than exposures to an aggregate vol-of-vol factor. Furthermore, we examine several possible other explanations for our results that are not related to uncertainty about risk and find that the vol-of-vol effect goes beyond these explanations. We propose a preference-based explanation that can explain the negative vol-of-vol effect and present initial evidence that supports this view: Uncertainty about risk affects financial markets not only in terms of expected stock returns, but also in terms of future trading activity. This is in line with an explanation based on investors who cease to participate in high vol-of-vol stocks because they are most averse to, or pessimistic about, uncertainty about risk. However, innovative testing or sophisticated modeling is needed to fully identify this explanation. Having established the empirical result that uncertainty about risk is strongly negatively priced, robust to many previously documented return predictors, relevant primarily as a characteristic rather than a factor, and influential on future trading activity, we leave such extensions for future research.

\section{Appendix. Variable Definitions}

Beta (BETA) is estimated for each stock $i$ at the end of month $t$ using a CAPM regression over 1 year of weekly returns. Specifically, we estimate $r_{i, \tau}-r_{\tau}^{f}=\alpha_{i}+\beta_{i, t} r_{\tau}^{M}+\varepsilon_{i, \tau}$, where $r_{i, \tau}$ is the return on stock $i$ over week $\tau, r_{\tau}^{M}$ is the market return in week $\tau$, and $r_{\tau}^{f}$ is the risk-free rate in week $\tau$. We proxy $r_{\tau}^{M}$ by the CRSP daily value-weighted index and $r_{\tau}^{f}$ by the Ibbotson risk-free rate. Beta equals the coefficient $\beta_{i, t}$.

Book-to-market (BOOK_TO_MARKET) is book equity divided by market capitalization at the end of the previous fiscal year, and is updated every 12 months beginning in July. Book equity is for the fiscal year ending in the preceding calendar year and equals the sum of stockholders' equity plus deferred taxes, investment tax credit, postretirement benefit assets net of liabilities, minus preferred stock.

Size (SIZE) is equity market capitalization (price times shares outstanding) at the end of the previous month. In our regressions we take the natural logarithm of size to remove the extreme skewness in this variable.

Momentum (MOMENTUM) is the cumulative stock return over the previous 11 months, that is, starting at time $t-12$ and ending at time $t-1$ to isolate momentum from the short-term reversal effect.

Short-term reversal (SHORT_TERM_REVERSAL) is last month's stock return (i.e., from time $t-1$ to time $t$ ). 
Idiosyncratic volatility (IDIOSYNC_VOLATILITY) for each stock $i$ is computed as the standard deviation of the daily residuals from the Fama-French (1993) 3-factor model. Specifically, we estimate $r_{i, \tau}-r_{\tau}^{f}=\alpha+\beta_{i, t} r_{\tau}^{M}+h_{i, t} \mathrm{HML}_{\tau}+s_{i, t} \mathrm{SMB}_{\tau}+\varepsilon_{i, \tau}$, where $r_{\tau}^{M}$ is the market return over period $\tau, \mathrm{HML}_{\tau}$ is the return of the value-minus-growth portfolio over period $\tau, \mathrm{SMB}_{\tau}$ is the return on the small-minus-big portfolio over period $\tau$, and $\varepsilon_{i, \tau}$ is the idiosyncratic return on stock $i$ over period $\tau$ using daily returns over rolling annual periods. Subsequently, we compute idiosyncratic volatility as the standard deviation of $\varepsilon_{i, \tau}$ over the past year.

Maximum return (MAXIMUM_RETURN) of each stock is the maximum daily return over the past month (i.e., from time $t-1$ to time $t$ ).

Skewness (SKEWNESS) is the historical third centralized moment calculated as $E(x-\mu)^{m} / \sigma^{m}=1 / N \sum_{t=1}^{n}\left(x_{i}-\bar{x}\right)^{m} / \hat{\sigma}_{x}^{m}$, where $\bar{x}$ and $\hat{\sigma}_{x}$ are the sample mean and standard deviation of daily returns on stock $i$ over the past year, and $m=3$. Barberis and Huang (2008) develop a behavioral setting in which positively skewed securities become overpriced and earn negative average excess returns.

Kurtosis (KURTOSIS) is the fourth centralized moment calculated similarly with $m=4$. Vol-of-vol bears resemblance to kurtosis as the tails of the stock return distribution thicken when the variance of a normally distributed variable normal can take several values.

NYSE only (NYSE_ONLY) is a dummy variable equal to 1 for stocks traded on the NYSE, and 0 otherwise

Amihud (2002) illiquidity (AMIHUD_ILLIQUIDITY) is computed as the absolute value of daily returns divided by daily dollar volume (in millions) measured annually. For NASDAQ firms, volume is divided by 2 to account for interdealer double-counting.

Turnover (TURNOVER) equals last month's number of shares traded in stock $i$ as a percentage of total shares outstanding.

Option bid-ask spread (OPTION_BID_ASK_SPREAD) is computed as the previous month's average of the bid-ask spreads on ATM options.

At-the-money skew (ATM_SKEW) is the difference between IVs of the ATM call and put options at time $t$.

Out-of-the-money skew (OTM_SKEW) is the difference between the implied volatility of the OTM put options and the average of the IVs of the ATM call and put options at time $t$.

Implied volatility-realized volatility spread (IV_RV_SPREAD) is the difference between the average of the IVs of the ATM call and put options at time $t$, and last month's realized volatility computed from daily returns.

Change in the ATM call IV and change in ATM put IV ( $\triangle$ CALL_IV, $\triangle$ PUT_IV) equal the monthly first difference between time $t$ and time $t-1$ in the IVs of the ATM call or put options.

Age (AGE) equals the number of years up to time $t$ since a firm first appeared on the CRSP tapes. In our regressions, we take the natural logarithm of age to remove the extreme skewness in this variable.

Analyst coverage (ANALYST_COVERAGE) is the number of analysts following the firm over the last month.

Forecast dispersion (FORECAST_DISPERSION) is the standard deviation in analysts' next fiscal year's IBES earnings forecasts, scaled by price, all measured at time $t$.

Volatility (VOLATILITY) is the standard deviation of weekly returns of each stock $i$ over the past year ending at the end of month $t$. 
Private information (PRIVATE_INFORMATION) is calculated after running a regression of each stock's excess return on the excess return of the market index and of the index for industry $j$ to which stock $i$ belongs; $r_{i, t}-r_{t}^{f}=\alpha_{i}+\beta_{i, t}\left(r_{\tau}^{M}-r_{\tau}^{f}\right)+\gamma_{i, t}\left(r_{j, \tau}-r_{\tau}^{f}\right)+$ $\varepsilon_{i, t}$. Private information is measured as $1-R^{2}$ obtained from this regression. The regressions are run on weekly data over the past year up to time $t$ using the CRSP valueweighted market index, the value-weighted industry index based on a firm's 2-digit SIC industry classification, and $r_{t}^{f}$ from Ibbotson.

Leverage (LEVERAGE) is defined as 1 minus book equity (see the variable definition of book-to-market) divided by total assets (Compustat item code: AT), updated every 12 months beginning in July.

Stock price delay (STOCK_PRICE_DELAY) is calculated after running a regression of the weekly excess returns of stock $i$ on contemporaneous and 4 weeks of lagged returns on the market portfolio over the past year up to time $t, r_{i, t}-r_{t}^{f}=\alpha_{i}+\beta_{i, t}\left(r_{\tau}^{M}-\right.$ $\left.r_{\tau}^{f}\right)+\sum_{n=1}^{4} \delta_{i}^{(-n)}\left(r_{\tau-n}^{M}-r_{\tau}^{f}\right)+\varepsilon_{i, t}$. Price delay equals 1 minus the ratio of the $R^{2}$ from the regression restricting $\delta_{i}^{(-n)}=0, \forall n \in[1,4]$ to the $R^{2}$ from the regression without restrictions, $1-\left(R_{R, i t}^{2} / R_{U, i t}^{2}\right)$.

Short-sale constraints (SHORT_SALE_CONSTRAINTS) are measured by "residual" institutional ownership (low institutional ownership indicates high short-sale constraints), calculated as institutional ownership corrected for size effects. Following Nagel (2005), we use the residual from cross-sectional regressions of institutional ownership against firm size during each quarter. Institutional ownership is measured as the fraction of shares of stock $i$ held by institutional investors during the quarter before the latest earnings announcement, as reported on Thomson Reuters CDA/Spectrum Institutional (13F) Holdings. We set institutional ownership to 0 if no ownership data are available for a firm-quarter during the 180 days before the earnings announcement.

Changes in VIX ( $\triangle$ VIX) equal the first daily differences in the CBOE VIX.

Change in the slope of the implied volatility skew( $\triangle$ OPTION_SKEW) is calculated as the daily change in the difference between the IVs of the OTM put option (nearest to 0.95 strike-to-spot ratio) and the average of the IVs of the nearest to ATM call and put options, where the options are nearest to 1-month maturity S\&P 500 index options.

\section{References}

Abdellaoui, M.; A. Baillon; L. Placido; and P. Wakker. "The Rich Domain of Uncertainty: Source Functions and Their Experimental Implementation.” American Economic Review, 101 (2011), $695-723$.

Ahn, D.; S. Choi; D. Gale; and S. Kariv. "Estimating Ambiguity Aversion in a Portfolio Choice Experiment." Quantitative Economics, 5 (2014), 195-223.

Ali, A.; L. Hwang; and M. Trombley. "Arbitrage Risk and the Book-to-Market Anomaly." Journal of Financial Economics, 69 (2003), 355-373.

Amihud, Y. "Illiquidity and Stock Returns: Cross-Section and Time-Series Effects." Journal of Financial Markets, 5 (2002), 31-56.

Amihud, Y., and H. Mendelson. "Asset Pricing and the Bid-Ask Spread." Journal of Financial Economics, 17 (1986), 223-249.

An, B.-J.; A. Ang; T. Bali; and N. Cakici. "The Joint Cross Section of Stocks and Options." Journal of Finance, 69 (2014), 2279-2337.

Andrews, D. "Tests for Parameter Instability and Structural Change with Unknown Change Point." Econometrica, 61 (1993), 821-856.

Ang, A.; J. Chen; and Y. Xing. "Downside Risk." Review of Financial Studies, 19 (2006), 1191-1239.

Ang, A.; R. Hodrick; Y. Xing; and X. Zhang. "The Cross-Section of Volatility and Expected Returns." Journal of Finance, 61 (2006), 259-299.

Ang, A.; R. Hodrick; Y. Xing; and X. Zhang. "High Idiosyncratic Volatility and Low Returns: International and Further U.S. Evidence.” Journal of Financial Economics, 91 (2009), 1-23. 
Bai, J., and P. Perron. "Estimating and Testing Linear Models with Multiple Structural Changes." Econometrica, 66 (1998), 47-78.

Bakshi, G., and N. Kapadia. "Delta-Hedged Gains and the Negative Market Volatility Risk Premium." Review of Financial Studies, 16 (2003), 527-566.

Bali, T., and N. Cakici. "Idiosyncratic Volatility and the Cross Section of Expected Returns." Journal of Financial and Quantitative Analysis, 43 (2008), 29-58.

Bali, T., and A. Hovakimian. "Volatility Spreads and Expected Stock Returns." Management Science, 55 (2009), 1797-1812.

Ball, R., and P. Brown. "An Empirical Evaluation of Accounting Income Numbers." Journal of Accounting Research, 6 (1968), 159-178.

Baltussen, G., and G. T. Post. "Irrational Diversification: An Examination of Individual Portfolio Choice." Journal of Financial and Quantitative Analysis, 46 (2011), 1463-1491.

Barberis, N., and M. Huang. "Mental Accounting, Loss Aversion, and Individual Stock Returns." Journal of Finance, 56 (2001), 1247-1292.

Barberis, N., and M. Huang. "Stocks as Lotteries: The Implications of Probability Weighting for Security Prices.” American Economic Review, 98 (2008), 2066-2100.

Battalio, R., and P. Schultz. "Options and the Bubble." Journal of Finance, 61 (2006), 2071-2102.

Beber, A.; J. Driessen; and P. Tuijp. "Pricing Liquidity Risk with Heterogeneous Investment Horizons.” Discussion Paper, Centre for Economic Policy Research (2011).

Bossaerts, P.; P. Ghirardato; S. Guarnaschelli; and W. Zame. "Ambiguity in Asset Markets: Theory and Experiment." Review of Financial Studies, 23 (2010), 1325-1359.

Brenner, M., and Y. Izhakian. "Asset Pricing and Ambiguity: Empirical Evidence." Working Paper, New York University (2012).

Campbell, J. "Intertemporal Asset Pricing without Consumption Data." American Economic Review, 83 (1993), 487-512.

Campbell, J. "Understanding Risk and Return.” Journal of Political Economy, 104 (1996), 298-345.

Cao, H.; T. Wang; and H. Zhang. "Model Uncertainty, Limited Market Participation, and Asset Prices." Review of Financial Studies, 18 (2005), 1219-1251.

Carhart, M. “On Persistence in Mutual Fund Performance.” Journal of Finance, 52 (1997), 57-82.

Chapman, D., and V. Polkovnichenko. "First-Order Risk Aversion, Heterogeneity, and Asset Market Outcomes." Journal of Finance, 64 (2009), 1863-1887.

Chen, J.; H. Hong; and J. Stein. "Forecasting Crashes: Trading Volume, Past Returns, and Conditional Skewness in Stock Prices.” Journal of Financial Economics, 61 (2001), 345-381.

Chen, Y.; P. Katuscak; and E. Ozdenoren. "Sealed Bid Auctions with Ambiguity: Theory and Experiments." Journal of Economic Theory, 136 (2007), 513-535.

Conte, A., and J. D. Hey. "Assessing Multiple Prior Models of Behaviour under Ambiguity." Journal of Risk and Uncertainty, 46 (2013), 113-132.

Cremers, M.; M. Halling; and D. Weinbaum. “Aggregate Jump and Volatility Risk in the Cross-Section of Stock Returns.” Journal of Finance, 70 (2015), 577-614.

Cremers, M., and D. Weinbaum. "Deviations from Put-Call Parity and Stock Return Predictability." Journal of Financial and Quantitative Analysis, 45 (2010), 335-367.

Cubitt, R.; G. van de Kuilen; and S. Mukerji. "Sensitivity towards Ambiguity: A Qualitative Test and a Measurement." Working Paper, University of Oxford (2012).

Daniel, K., and S. Titman. "Evidence on the Characteristics of Cross Sectional Variation in Stock Returns." Journal of Finance, 52 (1997), 1-33.

Daniel, K.; S. Titman; and K. Wei. "Explaining the Cross-Section of Stock Returns in Japan: Factors or Characteristics?" Journal of Finance, 56 (2001), 743-766.

Davis, J.; E. Fama; and K. French. "Characteristics, Covariances, and Average Returns: 1929 to 1997." Journal of Finance, 55 (2000), 389-406.

D’Avolio, G. "The Market for Borrowing Stock.” Journal of Financial Economics, 66 (2002), 271-306.

De Long, J.; A. Shleifer; L. H. Summers; and R. J. Waldmann. "Noise Trader Risk in Financial Markets." Journal of Political Economy, 98 (1990), 703-738.

Diether, K.; C. Malloy; and A. Scherbina. "Differences of Opinion and the Cross Section of Stock Returns." Journal of Finance, 57 (2002), 2113-2141.

Dimmock, S. G.; R. Kouwenberg; O. S. Mitchell; and K. Peijnenburg. "Ambiguity Attitudes and Economic Behavior." Working Paper No. 18743, National Bureau of Economic Research (2013).

Dimson, E. "Risk Measurement When Shares Are Subject to Infrequent Trading." Journal of Financial Economics, 7 (1979), 197-226.

Dittmar, R. "Nonlinear Pricing Kernels, Kurtosis Preference, and Evidence from the Cross Section of Equity Returns.” Journal of Finance, 57 (2002), 369-403. 
Dow, J., and S. Werlang. "Uncertainty Aversion, Risk Aversion, and the Optimal Choice of Portfolio." Econometrica, 60 (1992), 197-204.

Drechsler, I., and A. Yaron. "What's Vol Got To Do with It." Review of Financial Studies, 24 (2011), $1-45$.

Duarte, J.; X. Lou; and R. Sadka. “Option-Based Hedging of Liquidity Costs in Short Selling.” Working Paper, University of Washington (2005).

Easley, D., and M. O'Hara. “Ambiguity and Nonparticipation: The Role of Regulation." Review of Financial Studies, 22 (2009), 1817-1843.

Ellsberg, D. "Risk, Ambiguity, and the Savage Axioms." Quarterly Journal of Economics, 75 (1961), 643-669.

Ergin, H., and F. Gul. "A Theory of Subjective Compound Lotteries." Journal of Economic Theory, 144 (2009), 899-929.

Fama, E., and K. French. "Common Risk Factors in the Returns on Stocks and Bonds." Journal of Financial Economics, 33 (1993), 3-56.

Fama, E., and J. MacBeth. "Risk, Return, and Equilibrium: Empirical Tests." Journal of Political Economy, 81 (1973), 607-636.

Frazzini, A., and O. Lamont. "The Earnings Announcement Premium and Trading Volume.” Working Paper No. 13090, National Bureau of Economic Research (2007).

Frazzini, A., and L. H. Pedersen. "Betting against Beta." Journal of Financial Economics, 111 (2014), $1-25$.

Goetzmann, W. N., and A. Kumar. "Why Do Individual Investors Hold Under-Diversified Portfolios?" Working Paper, Yale School of Management (2005).

Halevy, Y. "Ellsberg Revisited: An Experimental Study.” Econometrica, 75 (2007), 503-536.

Harvey, C., and A. Siddique. "Conditional Skewness in Asset Pricing Tests." Journal of Finance, 55 (2000), 1263-1295.

Heath, C., and A. Tversky. "Preference and Belief: Ambiguity and Competence in Choice under Uncertainty." Journal of Risk and Uncertainty, 4 (1991), 5-28.

Hong, H., and D. Sraer. "Speculative Betas." Working Paper No. 18548, National Bureau of Economic Research (2012).

Klibanoff, P.; M. Marinacci; and S. Mukerji. "A Smooth Model of Decision Making under Ambiguity." Econometrica, 73 (2005), 1849-1892.

Levy, H. "Equilibrium in an Imperfect Market: A Constraint on the Number of Securities in the Portfolio." American Economic Review, 68 (1978), 643-658.

Lintner, J. "The Valuation of Risk Assets and the Selection of Risky Investments in Stock Portfolios and Capital Budgets." Review of Economics and Statistics, 47 (1965), 13-37.

Livnat, J., and R. R. Mendenhall. "Comparing the Post-Earnings Announcement Drift for Surprises Calculated from Analyst and Time Series Forecasts.” Journal of Accounting Research, 44 (2006), 177-205.

Mashruwala, C.; S. Rajgopal; and T. Shevlin. "Why Is the Accrual Anomaly Not Arbitraged Away? The Role of Idiosyncratic Risk and Transaction Costs." Journal of Accounting and Economics, 42 (2006), 3-33.

McNichols, M., and P. O'Brien. "Self-Selection and Analyst Coverage." Journal of Accounting Research, 35 (1997), 167-199.

Mendenhall, R. "Arbitrage Risk and Post-Earnings-Announcement Drift.” Journal of Business, 77 (2004), 875-894.

Merton, R. C. “A Simple Model of Capital Market Equilibrium with Incomplete Information.” Journal of Finance, 42 (1987), 483-510.

Miller, E. "Risk, Uncertainty, and Divergence of Opinion." Journal of Finance, 32 (1977), 1151-1168.

Nagel, S. "Short Sales, Institutional Investors and the Cross-Section of Stock Returns." Journal of Financial Economics, 78 (2005), 277-309.

Nau, R. "A Generalization of Pratt-Arrow Measure to Nonexpected-Utility Preferences and Inseparable Probability and Utility.” Management Science, 49 (2003), 1089-1104.

Nau, R. "Uncertainty Aversion with Second-Order Utilities and Probabilities." Management Science, 52 (2006), 136-145.

Neilson, W. S. "A Simplified Axiomatic Approach to Ambiguity Aversion." Journal of Risk and Uncertainty, 41 (2010), 113-124.

Newey, W., and K. West. "A Simple, Positive Semi-Definite, Heteroskedasticity and Autocorrelation Consistent Covariance Matrix.” Econometrica, 55 (1987), 703-708.

Polkovnichenko, V. "Household Portfolio Diversification: A Case for Rank-Dependent Preferences." Review of Financial Studies, 18 (2005), 1467-1502.

Pontiff, J. "Costly Arbitrage and the Myth of Idiosyncratic Risk." Journal of Accounting and Economics, 42 (2006), 35-52. 
Post, T., and H. Levy. "Does Risk Seeking Drive Stock Prices? A Stochastic Dominance Analysis of Aggregate Investor Preferences and Beliefs." Review of Financial Studies, 18 (2005), 925-953.

Ross, S. "The Arbitrage Theory of Capital Asset Pricing." Journal of Economic Theory, 13 (1976), $341-360$.

Segal, U. "The Ellsberg Paradox and Risk Aversion: An Anticipated Utility Approach." International Economic Review, 28 (1987), 175-202.

Segal, U. "Two-Stage Lotteries Without the Reduction Axiom." Econometrica, 58 (1990), 349-377.

Seo, K. "Ambiguity and Second-Order Belief." Econometrica, 77 (2009), 1575-1605.

Sharpe, W. "Capital Asset Prices: A Theory of Market Equilibrium under Conditions of Risk." Journal of Finance, 19 (1964), 425-442.

Shleifer, A., and R. Vishny. "The Limits of Arbitrage.” Journal of Finance, 52 (1997), 35-55.

Uppal, R., and T. Wang. "Model Misspecification and Underdiversification." Journal of Finance, 58 (2003), 2465-2486.

Wakker, P.; D. Timmermans; and I. Machielse. "The Effects of Statistical Information on Risk and Ambiguity Attitudes, and on Rational Insurance Decisions.” Management Science, 53 (2007), 1770-1784.

Yan, S. "Jump Risk, Stock Returns, and Slope of Implied Volatility Smile." Journal of Financial Economics, 99 (2011), 216-233.

Zhang, X. "Information Uncertainty and Stock Returns." Journal of Finance, 61 (2006), 105-137. 